\title{
Local stratification control of marine productivity in the subtropical North Pacific
}

\author{
Apurva C. Dave ${ }^{1}$ and M. Susan Lozier ${ }^{1}$ \\ Received 6 July 2010; revised 24 September 2010; accepted 1 October 2010; published 16 December 2010.
}

[1] Strengthened stratification of the upper ocean due to global warming is generally expected to inhibit marine primary productivity in the subtropics, based on the supposition that increased water column stability will decrease vertical mixing and consequently the entrainment of deep nutrients into the euphotic zone. A recent analysis of observational data from the subtropical North Atlantic, however, demonstrates that productivity in this region is not correlated with stratification on interannual time scales over the modern observational record, but is instead impacted by other dynamics that affect vertical mixing and nutrient supply. Herein, we examine data from the Hawaiian Ocean Time series program's Station ALOHA (A Long-Term Oligotrophic Habitat Assessment) in the subtropical North Pacific. We find that stratification and productivity are not strongly correlated at this location over the observational record. In contrast to the North Atlantic, the weakness of correlation observed at ALOHA may reflect the strongly stratified ecosystem of the eastern subtropical North Pacific and a lack of sufficiently strong interannual forcing in this region. Although basin-wide climate processes (namely El Niño-Southern Oscillation and Pacific Decadel Oscillation) have previously been suggested to impact local stratification and vertical nutrient supply at ALOHA, we find no evidence of a strong or consistent linkage. Comparing local ecosystem variability to the recently identified North Pacific Gyre Oscillation, however, we observe a correlation with local subsurface productivity and salinity. The correlations have similar structure in both space (i.e., depth) and time and are possibly linked to dynamics associated with the formation and advection of water masses in the central gyre.

Citation: Dave, A. C., and M. S. Lozier (2010), Local stratification control of marine productivity in the subtropical North Pacific, J. Geophys. Res., 115, C12032, doi:10.1029/2010JC006507.

\section{Introduction}

[2] Oceanographic literature has sustained a vigorous discussion on the physical forcing that drives spatial and temporal variability in marine primary productivity. A traditional conceptualization for the open ocean is that vertical mixing controls the availability of nutrients and light to surface photosynthesizers [Sverdrup, 1953; Lewis et al., 1986], and that this mixing is in turn constrained by local vertical density gradients (as described by Doney [2006]). Changes in density stratification and mixing are also thought to impact productivity by applying physiological pressure that selects for particular species within phytoplankton communities [Karl et al., 2001; Falkowski and Oliver, 2007; Dore et al., 2008]. From these assessments, the expectation has arisen that local stratification control can provide a

\footnotetext{
${ }^{1}$ Division of Earth and Ocean Sciences, Nicholas School of the Environment, Duke University, Durham, North Carolina, USA.

Copyright 2010 by the American Geophysical Union. 0148-0227/10/2010JC006507
}

mechanistic foundation for predictions of marine ecosystem response to a changing climate [Bopp et al., 2001; Boyd and Doney, 2002; Sarmiento et al., 2004; Schmittner, 2005; Cermeno et al., 2008].

[3] A number of recent observational studies have interpreted interannual and decadal variability in marine productivity within this theoretical framework [e.g., McClain et al., 2004; Gregg et al., 2005; Behrenfeld et al., 2006; Polovina et al., 2008; Irwin and Oliver, 2009]. A commonly developed narrative in many of these studies has been that strengthened stratification of the upper ocean, associated with either secular warming trends or climate oscillations, has increased energy requirements for overturning and subsequently reduced vertical mixing. In the tropical and subtropical oceans, where there is an ample supply of solar radiation, strengthened stratification is expected to negatively impact surface autotroph communities by decreasing the entrainment of deep, nutrient-rich water toward the surface. Two studies, in particular, present evidence for global, interannual decreases in productivity with increasing stratification. From an analysis of satellite-derived surface chlorophyll $a(\operatorname{chl} a)$, which is a widely used proxy for phytoplankton biomass, Behrenfeld et al. [2006] report a 
global decline in productivity that is associated with an increase in surface warming and stratification (measured as $\rho_{200}-\rho_{0}$ ) of tropical and subtropical waters in the aftermath of the 1997-1998 El Niño event. Similarly, Polovina et al. [2008] describe increases in the sea surface temperature (SST) and areal extents of the oceans' most oligotrophic regions over the period 1998-2006.

[4] A recent examination of interannual variability in subtropical upper ocean stratification and productivity, however, suggests that the two are not strongly correlated. In an analysis of data from the Bermuda Atlantic Time Series (BATS) program in the North Atlantic, M. S. Lozier et al. (On the relationship between upper ocean stratification and primary productivity in the oligotrophic North Atlantic, submitted to Geophysical Research Letters, 2010) demonstrate that local stratification (assessed as $\rho_{200}-\rho_{0}$ for consistency with Behrenfeld et al. [2006]) has essentially no correlative relationship with either surface chlorophyll concentrations or vertically integrated primary productivity on interannual time scales over the observational record, 19882008. In the same study, comparisons over the broader North Atlantic subtropical domain using satellite chl $a$ and historical hydrographic data yield similar results. Whether these regional observations are representative of the global subtropical ocean is not certain; to date, no similar comparisons have been made outside of the Atlantic. More importantly, the linkages between productivity and stratification variability that characterize the North Atlantic cannot be assumed to translate directly to other basins.

[5] The subtropical North Atlantic has traditionally been viewed as a system in which annual cycles of productivity are driven by seasonal destratification and strong mixing accompanied by nutrient entrainment from depth [Menzel and Ryther, 1961; Gruber et al., 2002]. In another important oligotrophic region, the vast subtropical North Pacific, the role of stratification appears to be qualitatively different. In general, the North Pacific has lower surface salinities, stronger stratification and shallower seasonal mixed layers than the Atlantic [Emery and Dewar, 1982; Lozier et al., 1995; Macdonald et al., 2001; Suga et al., 2004]. Previous ecosystem assessments in the subtropical North Pacific, including the ongoing Hawaiian Ocean Time series (HOT) program, demonstrate that the strong stratification restricts vertical mixing and deep nutrient inputs into the surface layer [Eppley et al., 1973; Letelier et al., 1993]. Unlike the subtropical North Atlantic, then, the subtropical North Pacific is a region in which annual variations in productivity are not principally driven by destratification. In such a setting, the sensitivity of productivity to future long-term changes in the mean stratification state may be difficult to predict. The modern observational record is a valuable tool in this regard, since it provides direct information on the historical relationship between variability in stratification and productivity and informs our predictions of what may happen to this relationship in the future. Toward that end, this study focuses on two decades of time series data collected at Station ALOHA (A Long-Term Oligotrophic Habitat Assessment), the primary field site of the HOT program. Our primary aim is to determine whether interannual variability in the density stratification of the local water column has impacted primary productivity over the observational record.

\section{Background}

\subsection{Controls on Subtropical Productivity}

[6] In general, the midlatitude upper ocean is characterized by a deep and strongly stratified euphotic zone in which a relatively shallow, nutrient-limited surface mixed layer with low levels of biomass allows enough light to pass through to support substantial photosynthesis and nutrient uptake at depth. This subsurface biological activity is evidenced by the persistent deep chlorophyll maxima (DCMs) that are ubiquitous in subtropical waters [Fennel and Boss, 2003; Huisman et al., 2006]. In this physical environment, patterns of productivity, nutrient cycling and phytoplankton community structure can vary significantly between the upper and lower euphotic zone [Venrick, 1982, 1993; Winn et al., 1995; Karl et al., 1996; Letelier et al., 2004; Corno et al., 2008]. This vertical ecosystem structure can be destroyed by deep convective mixing during the winter and spring, which would homogenize biomass distributions and instigate blooms of phytoplankton at the surface in two ways: through entrainment of deeper, nutrient-rich waters into the upper layer, and decoupling of grazing pressure from primary producers through reduced encounter rates between planktonic organisms [Behrenfeld, 2010]. It would be reasonable to expect, therefore, that subtropical marine productivity would be highly sensitive to interannual variability in stratification, yet the analysis of the subtropical North Atlantic by Lozier et al. (submitted manuscript, 2010) suggests otherwise.

[7] What can account for the lack of a strong interannual association between subtropical stratification and productivity? One explanation is that local stratification is only one of many factors that control vertical mixing. Interannual variability in wind and buoyancy forcing, both processes that destroy stratification and provide energy for mixing, has been shown to influence the timing and magnitude of phytoplankton blooms in the North Atlantic [Follows and Dutkiewicz, 2002; Ueyama and Monger, 2005]. The analysis at BATS by Lozier et al. (submitted manuscript, 2010) in particular, shows that mixing energy inputs from winds have consistently exceeded stratification-imposed energy requirements for overturning during bloom months over the past two decades. Local vertical mixing, in turn, is only one of many factors that impact nutrient supply to surface photosynthesizers. Horizontal surface Ekman transports from bordering subpolar regions have been shown to produce a significant influx of nutrients into the subtropics [Williams and Follows, 1998; Ayers and Lozier, 2010]. In addition, interannual variability in the formation and subsequent advection of subtropical mode waters around the gyre has been shown to exert a strong control on the basinwide subsurface nutrient reservoir and, consequently, the surface productivity that is fueled by upward fluxes of deep nutrients [Palter et al., 2005].

[8] In a sufficiently stratified region, however, mixing energy provided by surface winds or buoyancy changes may not be sufficient to induce vigorous seasonal overturning, resulting in a euphotic zone that is essentially permanently 


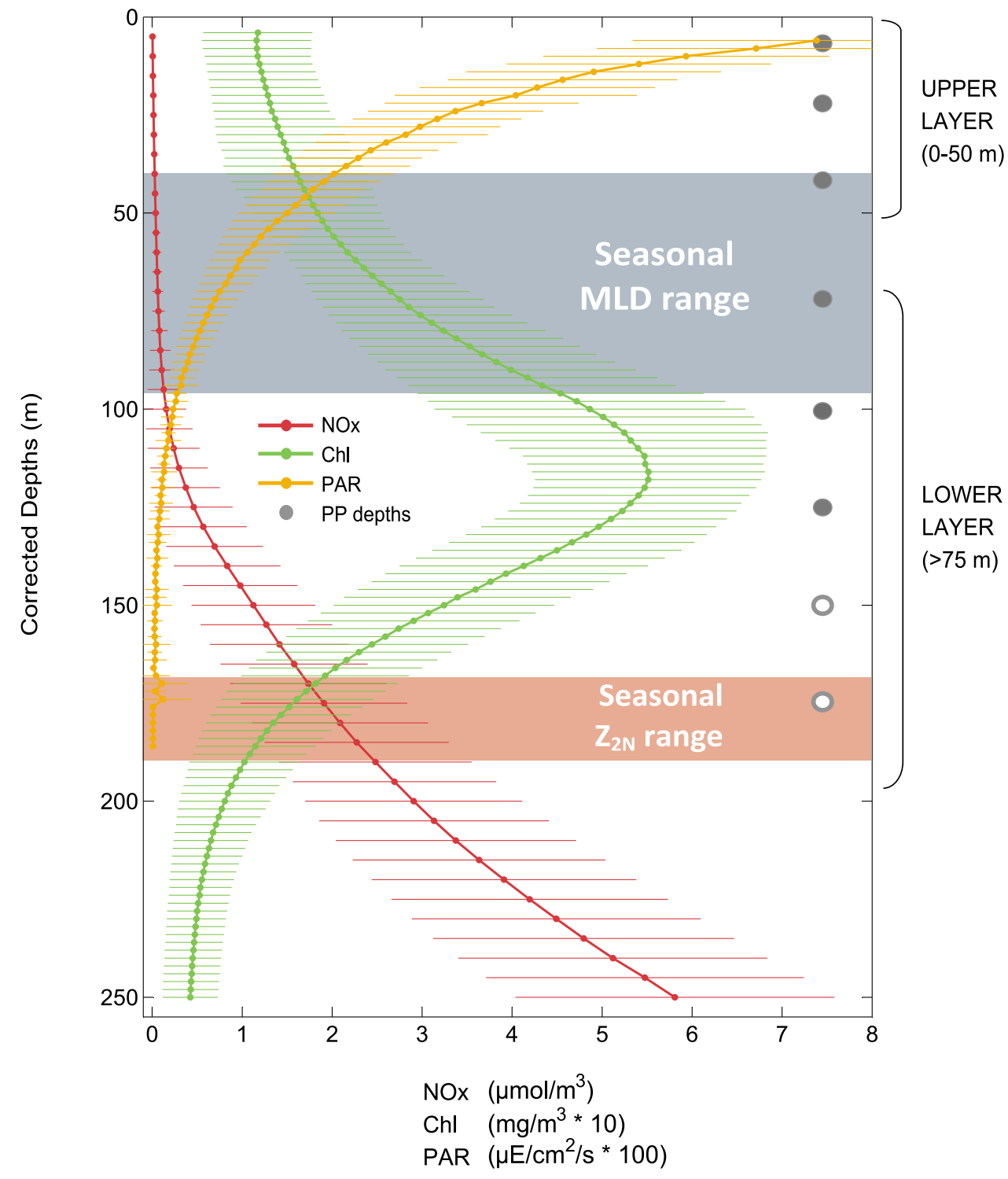

Figure 1. Long-term average (1988-2008) vertical profiles of downwelling photosynthetically available radiation $\left(\mu \mathrm{E} / \mathrm{m}^{2} / \mathrm{s}\right.$, yellow line), CTD chloropigments (chlorophyll $a$ and pheopigment, $\mathrm{mg} / \mathrm{m}^{3}$, green line), and nitrate plus nitrite ( $\mu \mathrm{mol} / \mathrm{kg}$, red line) measured at HOT Station ALOHA. See section 3 for description of how "corrected depth" profiles were generated. For each profile the bars indicate \pm 1 standard deviation. Shaded regions showing the seasonal ranges of the surface mixed layer depth (blue) and the $2 \mu \mathrm{mol} / \mathrm{kg} \mathrm{NOx}\left(\mathrm{NO}_{3}+\mathrm{NO}_{2}\right)$ isoline (red) are plotted for comparison. Properties have been scaled to fit on the same horizontal axis. Grey circles indicate standard depths of primary productivity measurements; the open circles correspond to 150 and $175 \mathrm{~m}$ measurements that were discontinued in 2000. The upper and lower layers of the euphotic zone are indicated with brackets.

divided into upper and lower layers. Station ALOHA in the eastern subtropical North Pacific provides an example of such a system (Figure 1). Over the past two decades mixed layer depths at this location have rarely exceeded $100 \mathrm{~m}$, with seasonal range of 36-96 m and a long-term mean of $60 \pm 24 \mathrm{~m}(1 \sigma)$. By comparison, the nutricline depth at this location (defined here as the $2 \mu \mathrm{mol} \mathrm{kg}^{-1}$ horizon of nitrate plus nitrite concentrations $\left[\mathrm{NO}_{3}+\mathrm{NO}_{2}\right]$ or "NOx") has a seasonal range of 170-191 m (with a long-term mean of $180 \pm 25 \mathrm{~m})$. As a consequence, nutrient supply from depth is perpetually restricted and nutrient levels in the surface mixed layer are almost completely depleted by biological uptake. Standing stocks of biomass upper $50 \mathrm{~m}$ are similarly low, with bulk chloropigment concentrations of $0.14 \pm 0.06 \mathrm{mg} \mathrm{m}^{-3}$. Due to the lack of light-attenuating compounds at the surface, photosynthetically available radiation (PAR) is sufficiently intense at depth to support a persistent and pronounced DCM centered at $\sim 125 \mathrm{~m}$.

[9] The vertical ecosystem structure illustrated in Figure 1 has historically been described by a two-layer ecological model for the subtropical North Pacific [Dugdale, 1967; Eppley et al., 1973] (modified by Dore et al. [2008]). In this 
model, the upper layer represents a light-replete, chronically nutrient-limited regime and the lower layer a light-limited and relatively nutrient-replete regime. In this context, it is difficult to imagine a single, unified response of productivity across the euphotic zone to interannual stratification variability. Recent research has focused on spatial and temporal changes in phytoplankton community structure and, in particular, on the contributions of nitrogen fixing organisms to the surface nutrient pool and to export production [Karl et al., 2001; Dore et al., 2002; White et al., 2007; Church et al., 2009]. In the lower euphotic zone, where deep nutrients are more readily available, vertical density gradients might be expected to play a significant role in controlling upward fluxes of nutrients from depth, but the interannual association between stratification and productivity in this layer has not yet been described. In the upper layer, where nutrient inputs are already severely restricted, the extent to which interannual increases in the mean stratification state would impact nutrient supply also remains an open question.

\subsection{Linkages to Climate}

[10] Although the subtropical North Pacific gyre contains some of the lowest levels of biomass observed in the global ocean, the region also exhibits pronounced fluctuations in primary productivity, particulate export and phytoplankton community structure over a range of time scales [ Karl, 1999]. It has been suggested that interannual and decadal ecosystem variability observed at Station ALOHA is driven by basin-wide climate processes (namely El Niño-Southern Oscillation (ENSO) and Pacific Decadel Oscillation (PDO)) which impact local stratification and, consequently, vertical nutrient transfers [Karl et al., 1995, 2001; Dore et al., 2002; Corno et al., 2007; Bidigare et al., 2009]. Although no clear physical linkage between climate variability and stratification changes at this location has yet been detailed, suggested mechanisms include changes in local cloud cover, wind forcing, the hydrological cycle, as well as advection of anomalous T/S properties [Lukas, 2001; Dore et al., 2002; Corno et al., 2007; Bidigare et al., 2009].

[11] Whatever the mechanistic linkages involved, climatedriven changes in nutrient supply have been suggested to drive significant changes in export production and phytoplankton assemblages at ALOHA. Within the autotroph community in particular, decreases in nutrient supply from depth are thought to be responsible for an observed domain shift from larger to smaller phytoplankton (which are better able to absorb nutrients from solution) as well as increases in diazotrophs (which are able to fix their own nitrogen) [Karl et al., 2001]. The response of primary productivity or particulate export at ALOHA to a given ENSO or PDO state, however, has not been uniform. Explanations for this lack of consistency have tended to focus on the complex and nonlinear dynamics internal to the local biology, time delays associated with transmission of the climate forcing, as well as interactions and interferences between ENSO and PDO signals [Dore et al., 2002; Corno et al., 2007; Bidigare et al., 2009]. One additional mode of climate variability that could explain ecosystem variability at Station ALOHA and that has not yet been compared to the HOT data set, is the recently identified North Pacific Gyre Oscillation (NPGO). The NPGO has been suggested to drive fluctuations in bio- geochemically relevant properties (salinity, nutrients, chlorophyll) within ecosystems of the Northeastern Pacific that do not appear to be strongly forced by PDO or ENSO [Di Lorenzo et al., 2008]. NPGO variations reflect changes in regional and basin-scale wind-driven upwelling/downwelling and advection, processes that are fundamental to controlling productivity in the subtropical gyres. A natural inquiry to make, therefore, is how NPGO variability is correlated (if at all) to ecosystem changes at ALOHA.

[12] The impact that climate processes have on physical and biological properties at ALOHA must also be considered in the context of the two-layer ecosystem model described earlier. For example, interannual changes in the density field that are associated with surface heat and freshwater fluxes may affect productivity differently than changes caused by subsurface advection of T/S properties. Similarly, the nutrient-limited upper layer might respond differently to interannual changes in cloud cover than the light-limited lower layer. An interesting question to consider, then, is whether there might also be vertical structure in the response of the local ecosystem to climate forcing, with stronger correlations observed at some depths than at others.

[13] The task of determining correlations between climate processes and ecosystem changes at ALOHA is made more arduous by the issue of time delays in local ecosystem response to climate perturbations that originate in the far field. No clear picture has yet emerged as to how long it takes for the effect of these perturbations to be expressed in either stratification or productivity variability at this location. Estimates in the literature range from to 10 months [Dore et al., 2002] to 2-3 years [Corno et al., 2007], the former based on a lag correlation analysis, the latter being based on theoretical considerations. To date, no comprehensive analysis has been made of the temporal structure (i.e., time lags) of correlations between climate processes and stratification and productivity at ALOHA.

\subsection{Study Objectives}

[14] Determination of the relationship between stratification and productivity variability is crucial to understanding the long-term physical drivers of productivity in the subtropical oceans. The North Pacific subtropical gyre is of particular importance since it is the largest of the major oligotrophic regions and accounts for a significant portion of global productivity and export. In this study, we use the HOT data set to address the following two sets of questions:

[15] 1 . How is interannual variability in primary productivity in the subtropical North Pacific related to variability in the density stratification of the local water column? How can this relationship be interpreted within the context of a two layer model (i.e., in the upper and lower euphotic zone)?

[16] 2. How is interannual variability in stratification and productivity in this region impacted by basin-wide climate variability? What is the spatial (i.e., vertical) and temporal structure of any correlations that do exist?

\section{Methods}

\subsection{Hydrographic and Biogeochemical Data}

[17] For this analysis we examine data from the HOT program's deep water hydrostation ALOHA (nominally 
located at $22^{\circ} 45^{\prime} \mathrm{N}, 158^{\circ} \mathrm{W}, 4750 \mathrm{~m}$ depth), at which extensive hydrographic and biogeochemical measurements have been made at approximately monthly intervals since 1988. This data set provides detailed assessments of the local ecology and its physical environment over seasonal to decadal time scales [Karl and Lukas, 1996]; the core HOT data include continuous vertical temperature and salinity profiles, as well as discrete measurements of inorganic nutrients, phytopigment concentrations, primary production rates, particulate fluxes and plankton assemblages. Qualitycontrolled data are available online, along with detailed information about the program's analytical methods, at http://hahana.soest.hawaii.edu/hot/hot jgofs.html. In addition, solar irradiance data, including surface-incident photosynthetically available radiation (PAR) fluxes and vertical profiles of downwelling PAR fluxes, have been measured at Station ALOHA concurrently with the core observations since 1998. These data are managed by the Oregon State University Remote Sensing Ocean Optics (ORSOO) group and are available in their raw form online at http://picasso. oce.orst.edu/ORSOO/data.html. We have employed quality control procedures outlined by Letelier et al. [2004] to prepare these data for analysis. Briefly, for the vertical PAR profiles, we have discarded values measured during the downcasts of the profiling sensor (due to stability issues) and at all other intervals when the sensor was tilted greater than $5^{\circ}$ with respect to the vertical, as well as all measurements shallower than $10 \mathrm{~m}$ (due to optical effects associated with surface turbulence). The remaining data were depth averaged into $2 \mathrm{~m}$ bins, to match the sampling resolution of the conductivity-temperature-depth (CTD) data.

[18] In addition to the in situ chlorophyll data, we also examine gridded 8 day mean fields of satellite-derived surface chlorophyll concentrations from the SeaWiFS data set (provided by NASA GSFC and available online at http:// oceancolor.gsfc.nasa.gov). The data are mapped on a $1 / 12^{\circ}$ grid and span the second half of the HOT time span, 19972008. We obtain local values of chl $a$ using the following two methods: (1) linearly interpolating values to the spatial location and date of each cruise at Station ALOHA and (2) spatially averaging chl $a$ concentrations within a $5^{\circ}$ box $\left(22^{\circ} \mathrm{N}, 160^{\circ} \mathrm{W}\right.$ to $\left.27^{\circ} \mathrm{N}, 155^{\circ} \mathrm{W}\right)$ that contains Station ALOHA.

\subsection{Isotopic Composition of Particulate Nitrogen Export Flux}

[19] We employ an isotopic mass balance calculation described by Dore et al. [2002] to deconvolve the export flux of particulate nitrogen $\left(\mathrm{F}_{\mathrm{PN}}\right)$ out of the euphotic zone (measured by sediment traps at $150 \mathrm{~m}$ depth) into components that are supported by nitrogen fixation $\left(\mathrm{F}_{\mathrm{PN}-\mathrm{N} 2}\right)$ and by the supply of nitrate $\left(\mathrm{NO}_{3}^{-}\right)$from depth $\left(\mathrm{F}_{\mathrm{PN}-\mathrm{NO} 3}\right)$

$$
\begin{gathered}
\delta^{15} \mathrm{~N}_{\mathrm{FPN}}=\left(\delta^{15} \mathrm{~N}_{\mathrm{N} 2}\right) * f_{\mathrm{N} 2}+\left(\delta^{15} \mathrm{~N}_{\mathrm{NO} 3}\right) * f_{\mathrm{NO} 3}, \\
\mathrm{~F}_{\mathrm{PN}-\mathrm{NO} 3}=\mathrm{F}_{\mathrm{PN}} * f_{\mathrm{NO} 3}, \\
\mathrm{~F}_{\mathrm{PN}-\mathrm{N} 2}=\mathrm{F}_{\mathrm{PN}} * f_{\mathrm{N} 2},
\end{gathered}
$$

where $\delta^{15} \mathrm{~N}$ represents nitrogen isotopic composition and $f_{\mathrm{NO} 3}$ and $f_{\mathrm{N} 2}$ are the $\mathrm{NO}_{3}^{-}$and $\mathrm{N}_{2}$-supported fractions of the $\mathrm{PN}$ flux, respectively. Implicit in this calculation are four basic assumptions [Dore et al., 2002]: that $\mathrm{F}_{\mathrm{PN}}$ is in balance with inputs into the euphotic zone of allochthonous nitrogen; that upward fluxes of $\mathrm{NO}_{3}^{-}$, nitrogen fixation and $\mathrm{F}_{\mathrm{PN}}$ are the only significant fluxes of nitrogen into or out of the euphotic zone; that the isotopic compositions of the two end-members of our mass balance calculation, $\delta^{15} \mathrm{~N}_{\mathrm{N} 2}$ and $\delta^{15} \mathrm{~N}_{\mathrm{NO} 3}$, are $0 \%$ and $6.5 \%$, respectively; and that the sediment trap data for particulate fluxes are not affected by fractionation or another isotopic bias.

\subsection{Climate and Wind Data}

[20] The Multivariate ENSO Index (MEI) is used to assess variability in ENSO forcing. The MEI is calculated as the first principal component of a composite time series of six properties monitored in the tropical Pacific: sea level pressure, zonal and meridional components of surface wind, sea surface temperatures, surface air temperatures and cloud cover. The index is available online from the NOAA Climate Diagnostics Center at http://www.cdc.noaa.gov/people/ klaus.wolter/MEI/table.html. Positive and negative MEI values refer to El Niño and La Niña conditions, respectively. To assess variability in PDO forcing, we use the PDO index (PDOI). The index is obtained from the Joint Institute for the Study of the Atmosphere and Ocean and is available online at http://jisao.washington.edu/pdo/PDO.latest. The index is determined from the leading principal component of monthly SST anomalies in the North Pacific, poleward of $20^{\circ} \mathrm{N}$ [Mantua et al., 1997], and is strongly correlated with variability in atmospheric circulation around the Aleutian lowpressure system. Positive and negative index values refer to warm and cool PDO phases, respectively. To assess variability in NPGO forcing, we use the NPGO index, which is determined from the second principal component of sea surface height variability in the Northeast Pacific and, as such, is strongly correlated with fluctuations in the intensity of the geostrophic circulation in this region. The index is available online at http://ocean.eas.gatech.edu/npgo/. Positive and negative index values refer to more and less intense gyre circulations, respectively.

[21] To assess variability in the local wind field, we use gridded monthly mean surface wind fields from the QuikSCAT data set (provided by CERSAT and available online at http://www.ifremer.fr/cersat/en/). The data are mapped on a $0.5^{\circ}$ grid and span the second half of the HOT time span, 1999-2008; they include wind stress and wind stress curl values. We obtain local values of zonal wind speed and the wind stress curl using the following two methods: (1) linearly interpolating values to the nominal location of Station ALOHA and (2) spatially averaging monthly signals over a $5^{\circ}$ box $\left(22^{\circ} \mathrm{N}, 160^{\circ} \mathrm{W}\right.$ to $\left.27^{\circ} \mathrm{N}, 155^{\circ} \mathrm{W}\right)$ that contains Station ALOHA. Analyses of the QuikSCAT data set are hampered by its relatively short duration; in this respect, a longer record such as the NCEP/NCAR reanalysis (1948 to present) might be preferable. However, the topography of the Hawaiian Islands has long been known to influence local atmospheric circulation [Smith and Grubisic, 1993; Xie et al., 2001; Chelton et al., 2004], and, in this regard, the relatively coarse resolution NCEP data (mapped to a $2.5^{\circ}$ grid) are probably less descriptive of the wind field around Station ALOHA than the QuikSCAT data. 


\subsection{Data Analysis}

[22] Ecosystem assessments at Station ALOHA are made using a "burst-sampling" strategy, in which a series of 12 18 hydrocasts approximately $3 \mathrm{~h}$ apart span a complete inertial period $\left(\sim 31 \mathrm{~h}\right.$ at $\left.20^{\circ} \mathrm{N}\right)$ as well as multiple semidiurnal tidal periods. The resulting depth-averaged density profile effectively smoothes out variability in the density field that occurs at frequencies greater than the biological response time. Using a methodology similar to that of Letelier et al. [2004], we have calculated "corrected" depths for individual bottle samples by mapping their density values onto the average density profiles for their cruise. Solar irradiance data are similarly affected by high-frequency variability in cloud cover, which can dramatically change PAR on time scales that are too short to engender a productivity response. We have again adopted the methodology of Letelier et al. and obtained corrected downwelling PAR profiles using climatological surface PAR values to scale the values of PAR in the water column

$$
\mathrm{PAR}_{\mathrm{z} \text { corrected }}=\mathrm{PAR}_{\mathrm{z}} \times\left[\overline{\overline{\mathrm{PAR}_{0}}} \overline{\overline{\mathrm{PAR}_{0}}}\right],
$$

where $\mathrm{PAR}_{\mathrm{z}}$ is an instantaneous downwelling PAR flux measured at depth $z, \mathrm{PAR}_{0}$ is the concurrent measurement of PAR flux at the sea surface and $\overline{\mathrm{PAR}_{0}}$ is the corresponding long-term monthly mean surface PAR flux. We have calculated this long-term monthly mean in the following two ways: (1) as the mean of all surface PAR measurements made at ALOHA during a given month for the period 1998 to present and (2) as the mean of all satellite-derived (SeaWiFS, 1997 to present) PAR values for that month, interpolated to the nominal position of Station ALOHA.

[23] For our analysis of seasonal variability at Station ALOHA, we first average all observations of the relevant physical and biological parameters for a single cruise (i.e., the "cruise mean") and then prepare time series of their long-term monthly means. Plots comparing seasonal time series of different properties present the dynamic range of each property, calculated by normalizing the long-term monthly mean values to a scale of 0 to 1 . For our analysis of interannual variability, we calculate monthly anomalies of each property by subtracting the corresponding long-term monthly mean from each short-term (i.e., cruise) mean. To investigate linkages to basin-wide climate processes, we perform a lag correlation analysis between the MEI, PDOI and NPGO indices and a suite of time series describing upper and lower layer stability, surface physics (e.g., wind forcing, solar irradiance), primary productivity, particulate export and the nutrient field at Station ALOHA. All time series are smoothed using 3 month running means, and highly statistically significant linear correlation coefficients $(p<0.01)$ are calculated for a series of lag times, ranging from 0-96 months.

\section{Results and Discussion}

\subsection{Seasonal Variability}

[24] Based on the vertical ecosystem structure described in Figure 1, we delineate the upper and lower euphotic zone as the $0-50 \mathrm{~m}$ and $>75 \mathrm{~m}$ depth ranges, respectively. Average monthly time series of ecosystem properties in these layers at Station ALOHA are presented in Figure 2. The plot updates important historical findings regarding seasonal variability in the upper and lower euphotic zone at this location with data extending through 2008, incorporating more than a decade of additional measurements in some cases.

\subsubsection{Upper Layer}

[25] In the upper euphotic zone at Station ALOHA, chl $a$ is elevated during winter months when mixed layers are deeper and stratification is weaker (Figure 2a). This signal, however, is unlikely to result from productivity driven by entrainment of deep nutrients, since the nutricline here lies below the wintertime mixed layer. In fact, seasonal primary productivity is almost completely out of phase with chl $a$, in that it is elevated during the spring and summer months when stratification is increasing. In the absence of large seasonal inputs of allochthonous nutrients, the wintertime chl $a$ increase has been attributed to phytoplankton photoadaptation and changing photosynthetic efficiency with deeper mixing rather than to an actual increase in biomass [Venrick, 1993; Letelier et al., 1993; Winn et al., 1995]. This dynamic highlights the potential difficulties in using satellite-based estimates of chlorophyll concentrations from this region as a proxy for phytoplankton biomass.

[26] The observed summer productivity maximum is thought to reflect phytoplankton blooms that result from enhanced nitrogen fixation, which increases in response to a synchrony of several conditions which favor the growth of key diazotrophic species: increased light intensity, stronger thermal stratification that further restricts nitrogen supply from depth and a calm, less turbulent air-sea interface [Karl et al., 1995; Dore et al., 2002; Grabowski et al., 2008; White et al., 2007; Church et al., 2009]. The strong, positive seasonal correlation $(r=0.92, p<0.05)$ of upper euphotic zone primary production with the fraction of particulate nitrogen flux out of the euphotic zone that contains recently fixed nitrogen $\left(\mathrm{F}_{\mathrm{PN}-\mathrm{N} 2}\right)$ is indicative of the importance of diazotroph activity (Figure 2b). Upper layer primary production is also negatively correlated with the square of the QuikSCAT wind speed (Figure 2c), but this statistical association is weak $(r=-0.35, p=0.24)$. The available wind data therefore do not appear to offer a clear answer to the question of whether upper layer productivity is enhanced during periods of relative surface calmness. Approximately $80 \%$ of all nitrogen fixation at Station ALOHA occurs within $60 \mathrm{~m}$ of the surface, and evidence suggest that diazotrophs account for up to half of vertically integrated new production in this region [Karl et al., 1997; Dore et al., 2002, 2008]. Collectively, these findings challenge traditional conceptions of local stratification control, since they suggest that significant seasonal inputs of new nitrogen into the euphotic zone of the subtropical North Pacific result from increased stability in the upper layer.

\subsubsection{Lower Layer}

[27] As described in the two-layer model, phytoplankton in the lower euphotic zone enjoy higher nutrient availability from the nutricline, but are also light limited. An important driver of annual cycles in productivity and nutrient uptake in this layer therefore is the seasonal evolution of the light field, which is shaped by the variations in solar radiation at the surface as well as changing concentrations of chloro- 
a) PP, chla and strat
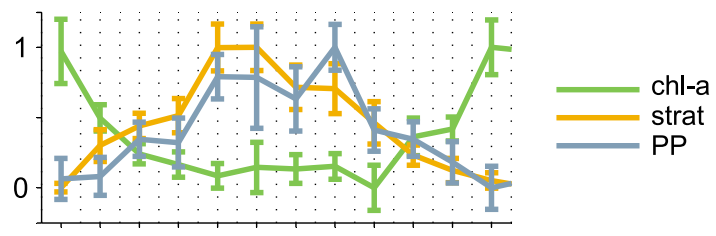

b) PP and $\mathrm{N}_{2}$-supported PN flux
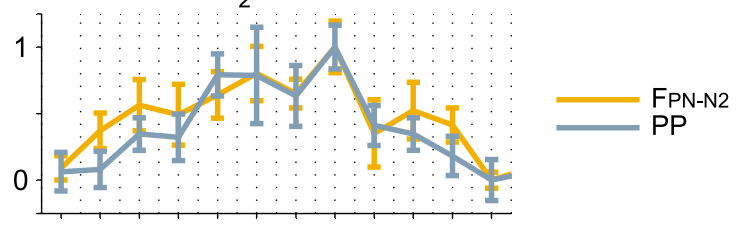

c) PP and surface wspd ${ }^{2}$

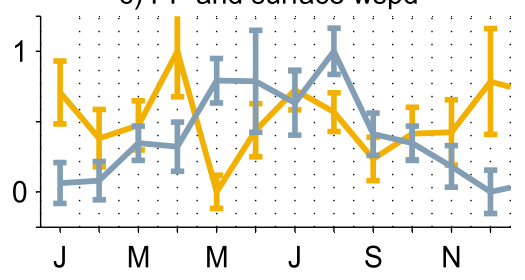

d) strat and $\mathrm{NO}_{3}$-supported PN flux

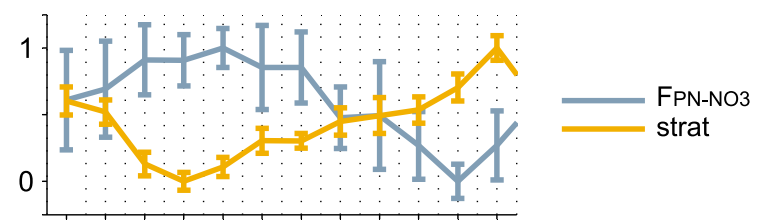

e) DCM and 0.001 PAR horizon

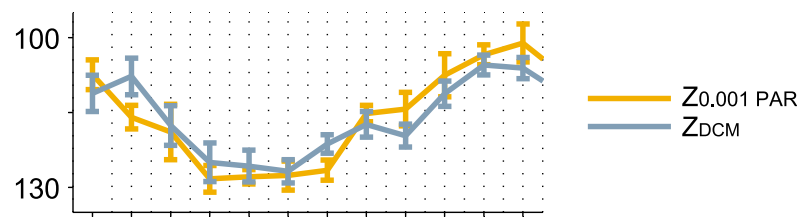

f) PP, PAR, NOx and SRP

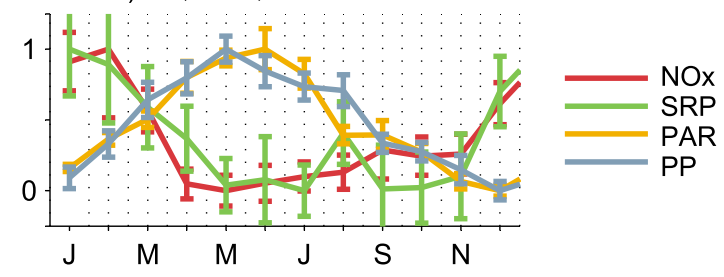

Figure 2. Seasonal time series of average monthly $(a-c)$ upper and $(d-f)$ lower euphotic zone properties at HOT Station ALOHA. Upper layer $(0-50 \mathrm{~m})$ stratification, average chlorophyll $a$, and integrated productivity (Figure 2a); upper layer integrated productivity with the $\mathrm{N}_{2}$-supported PN flux out of the euphotic zone (measured at $150 \mathrm{~m}$, Figure 2b); upper layer integrated productivity with the square of the average monthly QuikSCAT wind speed (Figure 2c); lower euphotic zone $(75-150 \mathrm{~m})$ stratification, average chl $a$, integrated productivity, and nitrate-supported PN flux (Figure 2d); depth of the DCM and the $0.001 \mu \mathrm{E} / \mathrm{cm}^{2} / \mathrm{s}$ PAR downwelling flux horizon (Figure 2e); and PAR downwelling flux measured near the top of the lower layer $(\sim 100 \mathrm{~m})$ with lower layer integrated primary productivity and chl $a$ concentrations (Figure 2f). NOx and soluble reactive phosphate (SRP) concentrations on the 24.5 sigma isopycnal surface. Bars indicate standard errors. Dynamic ranges of properties (0-1) have been plotted for Figures 2a-2d and 2f; Figure 2e shows absolute depths in meters.

phyll and other light-absorbing substances in the water column. Letelier et al. [2004] have shown that productivity levels and nutrient inventories in the lower euphotic zone track the seasonal penetration of isolumes. Our analysis confirms that the depth of the DCM closely follows the $0.001 \mu \mathrm{E} \mathrm{cm} \mathrm{cm}^{-2} \mathrm{~d}^{-1}$ PAR flux horizon throughout the year (Figure 2e). Moreover, summertime nitrate and phosphate concentrations along isopycnals in the lower layer are depleted relative to wintertime concentrations, as a result of increased uptake by phytoplankton during months with greater light intensity (Figure 2f). Productivity and phytoplankton biomass are greater during these months and exhibit a strong springtime increase that is analogous to the surface bloom events observed in light-limited waters at higher latitudes [Letelier et al., 2004].

[28] Productivity in the lower layer may also be impacted by annual cycles of stratification at the base of the euphotic zone. Since significant nitrogen fixation does not occur at these depths, upward fluxes from the deep nutrient pool are critically important for the maintenance of new production and the replenishment of depleted nitrogen and phosphorous in this layer. The data at Station ALOHA suggest that vertical density gradients may regulate these fluxes over seasonal time scales (Figure 2d). Lower layer stratification in the spring and early summer months is weaker than in the fall and winter and is negatively correlated with $\mathrm{F}_{\mathrm{PN}-\mathrm{NO} 3}$, ostensibly a measure of new lower layer production driven by deep nitrate $(\mathrm{r}=-0.82, \mathrm{p}<0.05)$. The correlation is consistent with the expectation that increased diffusivity due to weaker vertical density gradients would produce a greater upward flux of deep nutrients. In the lower layer, therefore, stratification appears to be related to seasonal productivity variability in a more conventional sense.

\subsection{Interannual Variability at Station ALOHA}

[29] The impact of stratification variability on productivity at Station ALOHA on interannual time scales is assessed by examining monthly anomalies for the period 1988-2008. A comparison of anomalies in depth-averaged chl $a$ and vertically integrated primary productivity with stratification, all assessed over the euphotic zone, shows no evidence of a correlative relationship (Figure 3a). Additional comparisons 

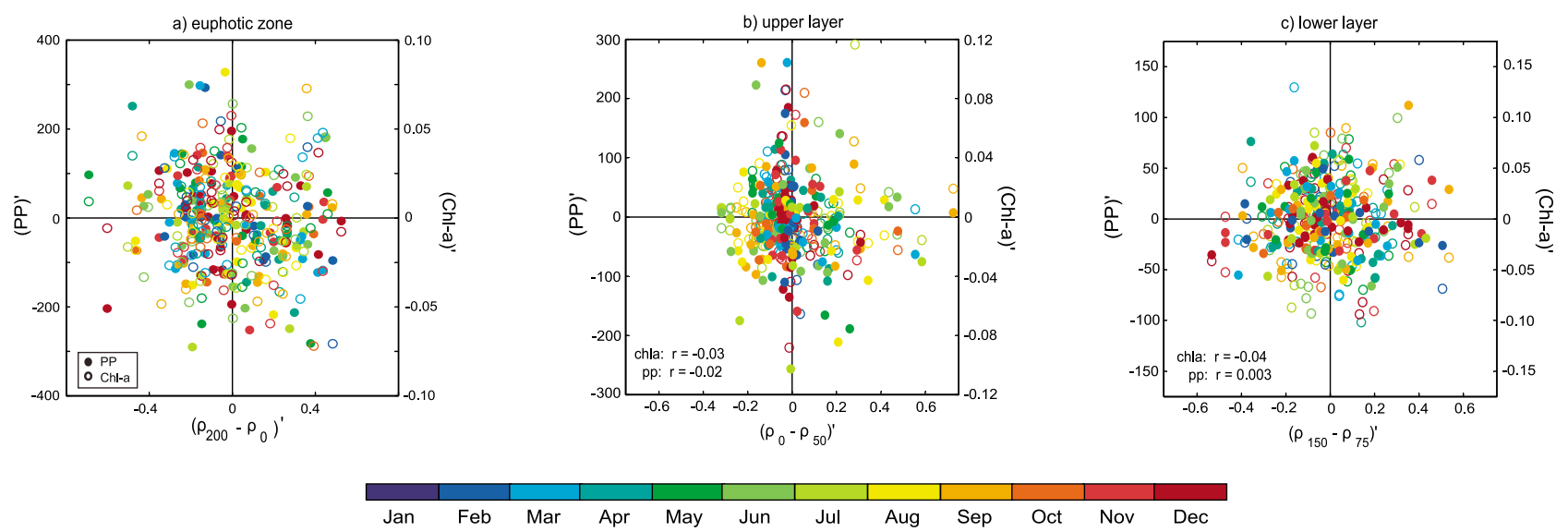

Figure 3. Monthly mean-subtracted anomalies of chlorophyll $a$ productivity versus stratification at Station ALOHA, 1988-2008. (a) Average chl $a$ concentrations $\left(0-150 \mathrm{~m}, \mathrm{mg} / \mathrm{m}^{3}\right.$, open circles) and vertically integrated primary production $\left(0-125 \mathrm{~m}, \mathrm{mg} \mathrm{C} / \mathrm{m}^{2} / \mathrm{d}\right.$, solid circles) versus stratification (assessed as $\rho_{200}-$ $\rho_{0}$ for consistency with Behrenfeld et al. [2006]); (b) for the upper layer, chl $a$ (primary productivity) is averaged (integrated) over $0-50 \mathrm{~m}$ and stratification is assessed as $\rho_{50}-\rho_{0}$; and (c) for the lower layer, chl $a$ (primary productivity) is averaged (integrated) over $75-150 \mathrm{~m}(75-125 \mathrm{~m})$ and stratification is assessed as $\rho_{150}-\rho_{75}$. The colors indicate the month of each observation.

using satellite-derived surface chl $a$ concentrations from the SeaWiFS data set in place of in situ values or mixed layer depths in place of stratification all yield similar results (not shown). Given the vertical ecosystem structure at this location, however, a single comparison over the entire euphotic zone may be overlooking dynamics occurring separately in the upper and lower euphotic zone. We extend our analysis to the upper and lower layers at Station ALOHA.

4.2.1. Stratification and Productivity in the Upper and Lower Layers

[30] A visual comparison of monthly anomalies in upper layer stratification (assessed as $\rho_{50}-\rho_{0}$ ) with chl $a$ concentrations and integrated primary productivity in the upper $50 \mathrm{~m}$ reveals no statistically significant correlations on interannual scales over the previous two decades (Figure 3b). When the comparison is repeated using mixed layer depth and other metrics that have previously been used to assess stratification in the euphotic zone, similar results are obtained (Table 1). No statistically significant correlations are found between stratification and primary productivity. Statistically significant $(\mathrm{p}<0.05)$ correlations do exist between surface chl $a$ and some of the stratification metrics, but, at most, only $13 \%$ of the observed chlorophyll variability can be explained by varying stratification. In any case, correlations between stratification and chl $a$ variability in the absence of correlations with productivity probably reflect physiological (photoadaptive) changes in phytoplankton rather than variability in biomass.

[31] One additional property related to upper layer productivity is the export of particulate organic matter out of the euphotic zone. If a steady state is assumed to exist between new production and particulate export (this entails assuming that export due to DOM transport or zooplankton migration is less important), then variability in the total particulate carbon flux $\left(\mathrm{F}_{\mathrm{PC}}\right)$ and the $\mathrm{N}_{2}$-supported fraction of the particulate nitrogen flux $\left(\mathrm{F}_{\mathrm{PN}-\mathrm{N} 2}\right)$ will reflect variability in net community production (NCP) across the euphotic zone and variability in the portion of new production in the upper

Table 1. Correlations Between Stratification and Productivity on Interannual Time Scales at Station ALOHA $^{\mathrm{a}}$

\begin{tabular}{|c|c|c|c|c|c|c|c|c|c|c|}
\hline \multirow[b]{2}{*}{ Stratification Metric } & \multicolumn{4}{|c|}{ Integrated Primary Productivity } & \multicolumn{4}{|c|}{ Average Chl $a$} & \multicolumn{2}{|c|}{$\underline{\text { PN Flux at } 150 \mathrm{~m}}$} \\
\hline & $0-50$ & $40-110$ & $75-125$ & $100-125$ & $0-50$ & $50-100$ & $75-125$ & $100-150$ & $\mathrm{PN}_{-}{ }_{\mathrm{NO}} 3$ & $\mathrm{PN}^{\mathrm{N} 2}$ \\
\hline MLD & - & 0.31 & 0.27 & 0.24 & 0.28 & -0.19 & - & - & - & 0.19 \\
\hline$\Delta \rho(0-50 \mathrm{~m})$ & - & -0.19 & -0.17 & - & - & 0.19 & - & - & - & - \\
\hline$\Delta \rho(50-100 \mathrm{~m})$ & - & -0.19 & -0.23 & -0.18 & -0.20 & - & - & - & - & -0.15 \\
\hline$\Delta \rho(75-125 \mathrm{~m})$ & - & - & - & - & -0.15 & - & - & - & - & - \\
\hline$\Delta \rho(100-150 \mathrm{~m})$ & - & - & - & - & - & - & - & - & 0.19 & - \\
\hline$\Delta \rho(150-200 \mathrm{~m})$ & - & - & - & - & - & - & - & - & - & - \\
\hline$\Delta \rho(0-(\mathrm{MLD}+20 \mathrm{~m}))$ & - & - & -0.16 & - & -0.24 & - & - & - & - & - \\
\hline$\Delta \rho((\mathrm{MLD}+20)-100 \mathrm{~m})$ & - & -0.22 & -0.20 & -0.17 & -0.35 & 0.15 & - & -0.15 & - & -0.15 \\
\hline$\Delta \rho((\mathrm{MLD}+20)-150 \mathrm{~m})$ & - & -0.21 & -0.17 & - & -0.36 & - & - & -0.16 & - & -0.19 \\
\hline$\Delta \rho / \Delta \mathrm{z}\left(\mathrm{DCM}-\mathrm{Z}_{2 \mathrm{~N}}\right)$ & - & - & - & - & - & - & - & - & 0.23 & - \\
\hline
\end{tabular}

${ }^{a}$ Statistically significant correlations $(\mathrm{p}<0.05)$ between interannual variability in local stratification metrics at Station ALOHA and interannual variability in upper and lower euphotic zone integrated primary production, upper and lower euphotic zone chlorophyll $a$ concentrations and particulate nitrogen $(\mathrm{PN})$ fluxes measured at the base of the euphotic zone $(150 \mathrm{~m})$. The correlation analysis is performed for monthly meansubtracted anomalies in each property over the period 1988-2008. Stratification metrics $\Delta \rho(0-(\mathrm{MLD}+20 \mathrm{~m})), \Delta \rho((\mathrm{MLD}+20)-100 \mathrm{~m})$, and $\Delta \rho((\mathrm{MLD}+20)-150 \mathrm{~m})$ are adopted from Corno et al. [2007, Figure 1]. Nonsignificant correlations are presented as dashes. 
Table 2. Correlations Between Productivity and Other Properties on Interannual Time Scales at Station ALOHA $^{\mathrm{a}}$

\begin{tabular}{|c|c|c|c|c|c|c|c|c|c|c|}
\hline & \multicolumn{4}{|c|}{ Integrated Primary Productivity } & \multicolumn{4}{|c|}{ Average Chl $a$} & \multicolumn{2}{|c|}{ PN Flux at $150 \mathrm{~m}$} \\
\hline & $0-50$ & $40-110$ & $75-125$ & $100-125$ & $0-50$ & $50-100$ & $75-125$ & $100-150$ & $\mathrm{PN}-\mathrm{NO} 3$ & $\mathrm{PN}^{-}{ }_{\mathrm{N} 2}$ \\
\hline Wind speed & - & - & - & - & 0.33 & - & - & - & - & - \\
\hline Wind stress curl & _- & - & - & - & - & - & _- & - & _- & - \\
\hline $\mathrm{PAR}$ at $0 \mathrm{~m}$ & - & 0.25 & 0.30 & 0.29 & - & _- & - & - & - & _- \\
\hline PAR at $50 \mathrm{~m}$ & N/A & - & - & - & $\mathrm{N} / \mathrm{A}$ & -0.20 & - & 0.23 & - & - \\
\hline PAR at $100 \mathrm{~m}$ & N/A & - & 0.23 & 0.21 & $\mathrm{~N} / \mathrm{A}$ & -0.37 & - & 0.27 & 0.26 & - \\
\hline$\sigma_{\theta}$ at $150 \mathrm{~m}$ & - & - & - & - & - & - & - & - & - & - \\
\hline$\sigma_{\theta}$ at $200 \mathrm{~m}$ & - & _- & - & _- & _- & - & - & - & _- & - \\
\hline$[\mathrm{NOx}]$ at $150 \mathrm{~m}$ & - & - & - & - & - & 0.20 & - & - & - & - \\
\hline$[\mathrm{NOx}]$ at $200-500 \mathrm{~m}$ & - & 0.18 & 0.18 & _- & _- & 0.22 & 0.22 & - & _- & - \\
\hline [SRP] at $150 \mathrm{~m}$ & - & -0.21 & -0.20 & -0.20 & - & 0.17 & - & - & - & - \\
\hline [SRP] at $200-500 \mathrm{~m}$ & - & 0.15 & 0.16 & - & - & 0.20 & 0.20 & - & - & - \\
\hline
\end{tabular}

\footnotetext{
${ }^{\mathrm{a}}$ As with Table 1 , statistically significant correlations $(\mathrm{p}<0.05)$ between variability in upper and lower euphotic zone integrated primary production, upper and lower euphotic zone chlorophyll $a$ concentrations and particulate nitrogen (PN) fluxes with a suite of physical properties measured or evaluated at ALOHA: QuikSCAT winds, photosynthetically available radiation, potential density at $150 \mathrm{~m}$ and $200 \mathrm{~m}$, and nutrient concentrations at and below the base of the euphotic zone. Here N/A means not applicable.
}

layer driven by nitrogen fixation, respectively [Dore et al., 2002; Brix et al., 2006]. The correlation between $\mathrm{F}_{\mathrm{PC}}$ and stratification (not shown) is not statistically significant for any measure of stratification. For $\mathrm{F}_{\mathrm{PN}-\mathrm{N} 2}$ we observe only a very weak association with some of the stratification metrics; these correlations are at most able to explain less than $4 \%$ of observed $\mathrm{F}_{\mathrm{PN}-\mathrm{N} 2}$ variability (Table 1 ).

[32] In the lower euphotic zone, a comparison of monthly anomalies in stratification (assessed as $\rho_{150}-\rho_{75}$ ) with chl $a$ concentrations and integrated primary productivity reveals no statistically significant correlations on interannual scales over the previous two decades (Figure 3c). As with the upper layer data, repetition of the comparison with an array of stratification metrics as well as a range of assessments of subsurface productivity and chlorophyll, yields similar results (Table 1). Less than $10 \%$ of the variance in any measure of depth-integrated productivity and $4 \%$ of the variance in any measure of depth-averaged chl $a$ can be explained by any of the measures of stratification variability. A comparison using $\mathrm{F}_{\mathrm{PN}-\mathrm{NO} 3}$ as an indicator of new lower layer production driven by deep nitrate also shows no clear association with stratification variability. At best, only $5 \%$ of the observed $\mathrm{F}_{\mathrm{PN}-\mathrm{NO} 3}$ variability is attributable to interannual stratification changes.

\subsubsection{Alternate Processes and Time Scales}

[33] An array of alternate local processes can be considered in place of stratification change as possible drivers of the observed biological variability on interannual time scales at Station ALOHA (Table 2). We compare productivity, chl $a$ and particulate export to changes in solar irradiance at the surface and at depth, local wind stirring and wind stress curl (which is directly related to Ekman pumping velocities), density values at the base of the euphotic zone (which would be sensitive to the heaving of deep isopycnals on seasonal and longer scales) and nutrient concentrations along isopycnals below the euphotic zone (which would indicate variability in the deep nutrient reservoir). Our analysis, however, finds no clear evidence of a correlative relationship between productivity and any of these properties.

[34] The choice of monthly time intervals is potentially significant for this temporal correlation for several reasons. First, the weak month-to-month correlations between particulate fluxes and stratification variability observed here may also simply reflect a temporal lag between the production of new biomass and its eventual export. In addition, the use of particulate flux data to infer productivity variability relies on an assumption of steady state between new production and export that becomes less robust on shorter time scales. Furthermore, the response of nitrogen fixing phytoplankton to strengthening of vertical density gradients may ultimately be dependent on the duration of the enhanced stratification state [Dore et al., 2002]. The onset of greater stratification and a decrease in nutrient supply from depth would initially confer a competitive advantage to diazotrophs. This advantage could eventually disappear under conditions of prolonged, intense stratification, due to the depletion of other limiting nutrients such as phosphorous, leading to diazotroph population crashes. All of these issues could be at least partially addressed by averaging data over each season and each year of the HOT data set. Comparisons of data averaged over these intervals, however, again reveal no statistically significant correlations between any of our measures of upper and lower layer productivity and stratification.

[35] The results at Station ALOHA suggest that productivity does not respond linearly or even monotonically to changes in the mean stratification state. Comparisons focusing on intervals when the strongest stratification anomalies occur also yield the same result. Intriguingly, the strong biological and physical coupling observed here on seasonal time scales does not extend to interannual scales. The correlations that are observed on interannual time scales are extremely weak; when the test for significance is made more stringent $(\mathrm{p}<0.01)$, more than half of them disappear. The lack of a consistent biological response to even the strongest observed anomalies in any of the physical parameters suggests that a minimum forcing threshold may not yet have been reached.

\subsection{Linkages to Climate Variability}

[36] Forcing from ENSO and PDO has consistently been invoked to explain interannual and decadal scale ecosystem variability at Station ALOHA [Karl et al., 1995, 2001; Dore et al., 2002; Corno et al., 2007; Bidigare et al., 2009]. In the absence of a strong interannual association between stratification and productivity at this location, however, the linkage between local biological variability and climate 
variability (thought to be mediated by local stratification changes) appears tenuous. Direct comparisons of variability in HOT properties with either of the PDO or ENSO indices do little to strengthen the case for climate linkages. Given the time scales (20-30 years) associated with PDO cycles, the HOT record is probably too short for a robust correlation analysis. Comparisons with the higher-frequency ENSO signal can be made with greater statistical confidence, but the response of biology at Station ALOHA to a given ENSO state has been demonstrably inconsistent [Dore et al., 2002; Corno et al., 2007]. It may be that the forcing effects from these climate signals are not transmitted strongly to this position, or that, even if these effects are transmitted, complex interactions between the signals originating from the tropics (ENSO) and higher latitudes (PDO) produce an incoherent local expression at this intermediate $\left(\sim 20^{\circ} \mathrm{N}\right)$ location.

[37] In the absence of a direct correlation of local stratification and productivity with ENSO or PDO, recent studies have instead treated ecosystem variability at Station ALOHA as a function of the combined variability of the two climate processes. Corno et al. [2007], for example, argue that the records of local stratification, vertical nutrient delivery, productivity and community structure at Station ALOHA from 1988-2004 can be separated into intervals that are each characterized by a distinct pattern of phasing and relative intensity between ENSO and PDO. Similarly, Bidigare et al. [2009] assert that a strong, concurrent transition in both ENSO and PDO during the summer of 1998 forced a transition to a weaker stratification state leading to stronger vertical mixing, greater nutrient fluxes from depth and subsequent changes in plankton assemblages and particulate export at ALOHA. However, while a comparison of productivity rates before and after this 1998 ENSO/PDO shift does suggest a shift to higher productivity (most pronounced at "middle depths" within the euphotic zone), there is no clearly observable change in stratification before and after this transition, either in the surface layer or at the base of the euphotic zone (Figure 4).

[38] While much attention has been paid to the influence of ENSO and PDO fluctuations in driving ecosystem variability at Station ALOHA, the role of the recently identified North Pacific Gyre Oscillation has yet to be considered. Since NPGO variability reflects basin-wide changes in wind-driven circulation and has been correlated with nutrient and productivity variations elsewhere in the North Pacific [Di Lorenzo et al., 2008], this climate process is a natural candidate for comparison with the HOT data set. A temporal lag correlation analysis between the NPGO index and time series of stratification and productivity at ALOHA is shown in Figure 5. For visual comparison, we include correlations of these HOT properties with the Multivariate ENSO Index (MEI) and PDO Index (PDOI). Figures 5b-5d show statistically significant $(p<0.01)$ correlations of ENSO, PDO and NPGO variability with a range of metrics used to describe variability in local hydrography and primary productivity over the observational record at Station ALOHA. As discussed earlier, the comparison reveals no evidence of a strong or consistent interannual association between ENSO and PDO variations and variability in local stratification or productivity. A comparison with the NPGO, however, reveals an interesting pattern of relatively stronger correlations between this climate process and primary production as well as with specific features of the local hydrography. In each case the correlations persist over a large range of time lags, and this persistence probably reflects the strong low-frequency component of the NPGO signal. The correlations are discussed in detail below.

[39] Subsurface primary productivity at ALOHA is weakly positively correlated with NPGO variability for time lags of $0-50$ months. The correlations are maximized for "middle" and lower depths within the euphotic zone (45$100 \mathrm{~m}$ ) and for time lags between 12 and 18 months, but are able to explain at most $12.5 \%$ of the observed variability $(\mathrm{r}=$ 0.35 at 18 months). The $\mathrm{F}_{\mathrm{PC}}$ (related to total net community production) and $\mathrm{F}_{\mathrm{PN}-\mathrm{N} 2}$ fluxes (related to new production driven by nitrogen fixation) are also positively correlated with NPGO variability over a similar range of time lags, 0 33 months for $\mathrm{F}_{\mathrm{PC}}$ and $0-44$ months for $\mathrm{F}_{\mathrm{PN}-\mathrm{N} 2}$. The correlations are both maximized at 15 months, similar to primary productivity, and are able to explain up to $11 \%$ of the observed variability in $\mathrm{F}_{\mathrm{PC}}(\mathrm{r}=0.33)$ and $18 \%$ of the variability in $\mathrm{F}_{\mathrm{PN}-\mathrm{N} 2}(\mathrm{r}=0.43)$. It is interesting to note that no correlation is observed between NPGO variability and the $\mathrm{NO}_{3}$-supported fraction of the particulate flux, suggesting that the correlation between the NPGO and local productivity somehow involves diazotroph activity. Since most nitrogen fixation is confined to the upper $60 \mathrm{~m}$ at ALOHA, it is uncertain why we do not therefore observe a stronger correlation involving primary productivity nearer the surface.

[40] In contrast to the correlation observed between the NPGO index and local productivity variability, there is no equivalent association between NPGO variations and any of the metrics for stratification used in this study. Whatever the mechanisms that underlie the NPGO productivity correlation, it appears that this linkage is not mediated by local stratification changes. Interestingly, however, a strong, positive correlation is observed between the NPGO index and local subsurface salinity over a similar range of time lags and depths as the NPGO productivity correlations. These correlations extend to the surface but are maximized for "middle lower" euphotic zone (50-100 m and 100-150 m, abruptly weakening in waters $>150 \mathrm{~m}$ ) and for time lags between 12 and 18 months (again similar to the depths and time lags observed for the maximum NPGO productivity correlations). The correlations are able to explain up to $37 \%$ of the observed variability at $100-150 \mathrm{~m}(\mathrm{r}=0.61$ at 12 months). Salinity variability at these depths may be linked to the variability in North Pacific Tropical Water (NPTW), which is formed in frontal regions to the north and east of Hawaii characterized by high surface salinity. The subduction and subsequent advection of NPTW to Station ALOHA creates a persistent subsurface salinity maximum between the 24.3 and $24.7 \sigma_{\theta}$ isopycnals, which lie on average between 100 and $140 \mathrm{~m}$ in depth [Suga et al., 2000; Lukas, 2001; Lukas and Santiago-Mandujano, 2008; Stammer et al., 2008]. Variations in the intensity of the salinity maximum have been suggested to arise from changes in the surface heat and freshwater fluxes and dynamical convergences that produce the high-salinity signature of the NPTW source regions [Lukas, 2001]. The observed correlation between the NPGO and subsurface salinity at ALOHA, therefore, probably reflects the strong role of this climate process in driving the formation of NPTW and possibly other water masses in 


$$
\Delta \rho\left(\mathrm{kg} / \mathrm{m}^{3}\right)
$$
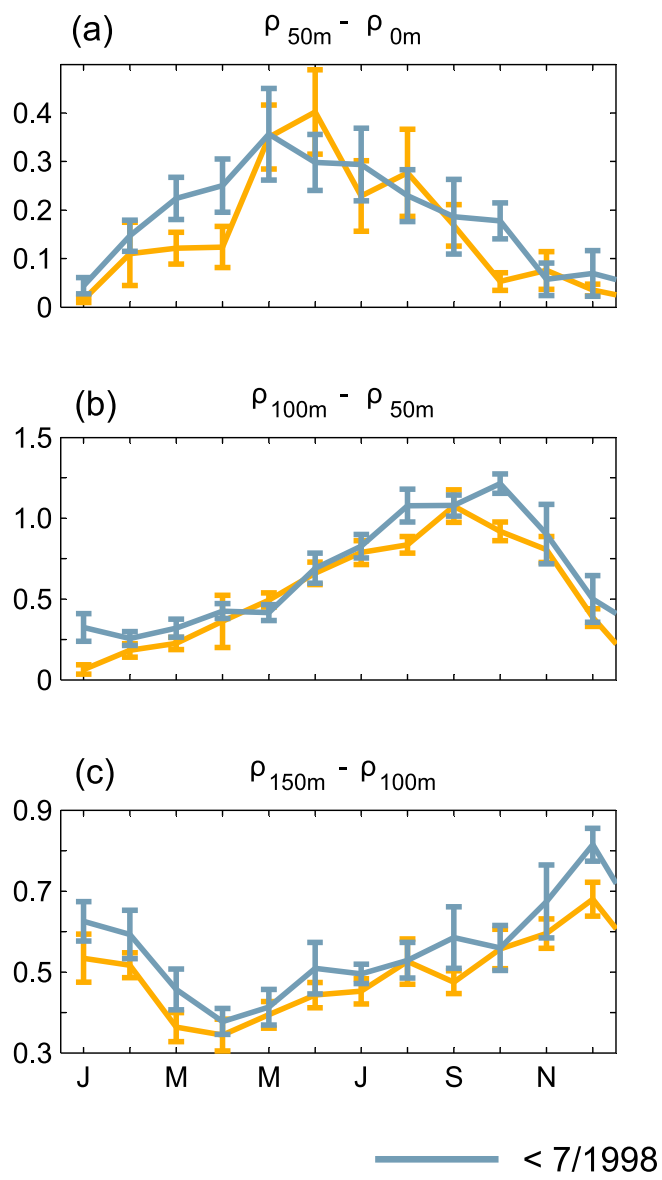

$\mathrm{PP}\left(\mathrm{mg} \mathrm{C} / \mathrm{m}^{3}\right)$

(d)

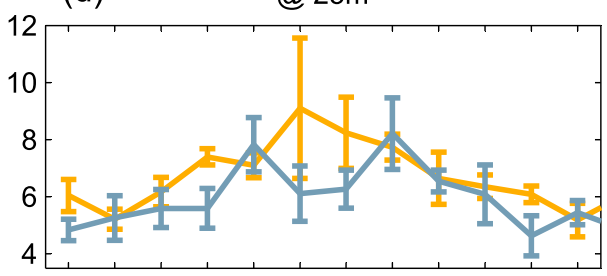

(e) @ 75m

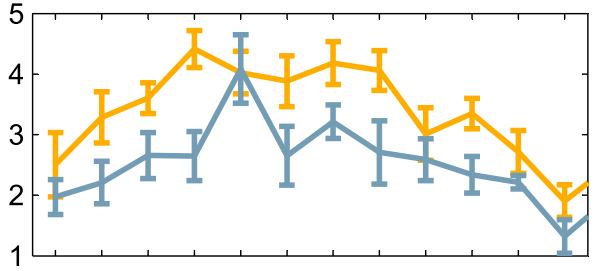

(f) @ 100m

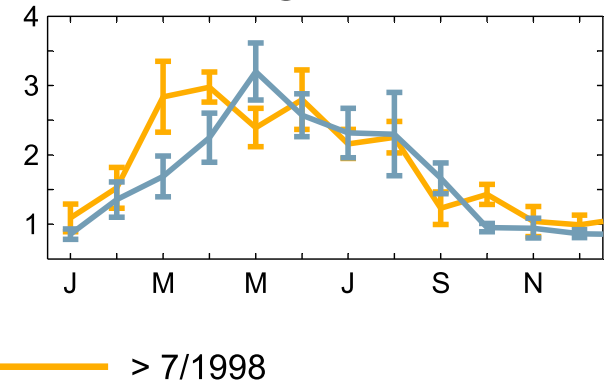

Figure 4. Comparison of stratification and primary productivity at Station ALOHA before and after the strong ENSO/PDO transition in July 1998. Average monthly values of stratification, assessed as the change in potential density (a) in the upper layer 0-50 m, (b) over 50-100 m, and (c) near the base of the euphotic zone 150-200 m. Average monthly values of primary productivity measurements (d) within the upper layer $25 \mathrm{~m}$, (e) at the transition between the upper and lower layers $75 \mathrm{~m}$, and (f) near the base of the euphotic zone $100 \mathrm{~m}$. The blue line corresponds to the time period before the transition, and the yellow line corresponds to the period following the transition. Bars indicate the standard errors.

the central subtropical gyre. The lag times for which the correlation between NPGO forcing and salinity variability is maximized, 12-18 months, are roughly consistent with time scales required for advection of NPTW from its source region to ALOHA [Lukas and Santiago-Mandujano, 2008]. Despite the similar spatial and temporal structure of the NPGO salinity and NPGO productivity correlations, it is unclear how subsurface salinity variability or NPTW variability can be mechanistically linked to changes in productivity and specifically to nitrogen fixation. One possible linkage may be that the nutrient content of NPTW varies concurrently with observed salinity changes, and that NPTW variability also produces variability in the local advective flux of nutrients transported by this water mass. An interesting future analysis would be to examine how "upstream" property changes in the source regions of the NPTW are related to both the NPGO and local productivity variability at ALOHA.

[41] Although the NPGO productivity correlations described above are weak, the overall pattern stands in sharp contrast to the absence of associations between the HOT data and ENSO/PDO variability. Even when we focus on the intervals within the record that are characterized by any combination of strong ENSO and PDO index values (i.e., |index| $>1$, see Figure 5a), no consistent pattern of correlation is observed between these climate processes and either stratification or productivity at ALOHA. In contrast, the NPGO variations correlate with local productivity and salinity variability over similar spatial (depth) and temporal scales patterns. Moreover, these correlations are observed in spite of the low degree of temporal smoothing (3 month moving averages) and a stringent significance threshold for reporting correlations $(\mathrm{p}<0.01)$. Although the mechanisms 
a) ENSO, PDO and NPGO indices over HOT time span
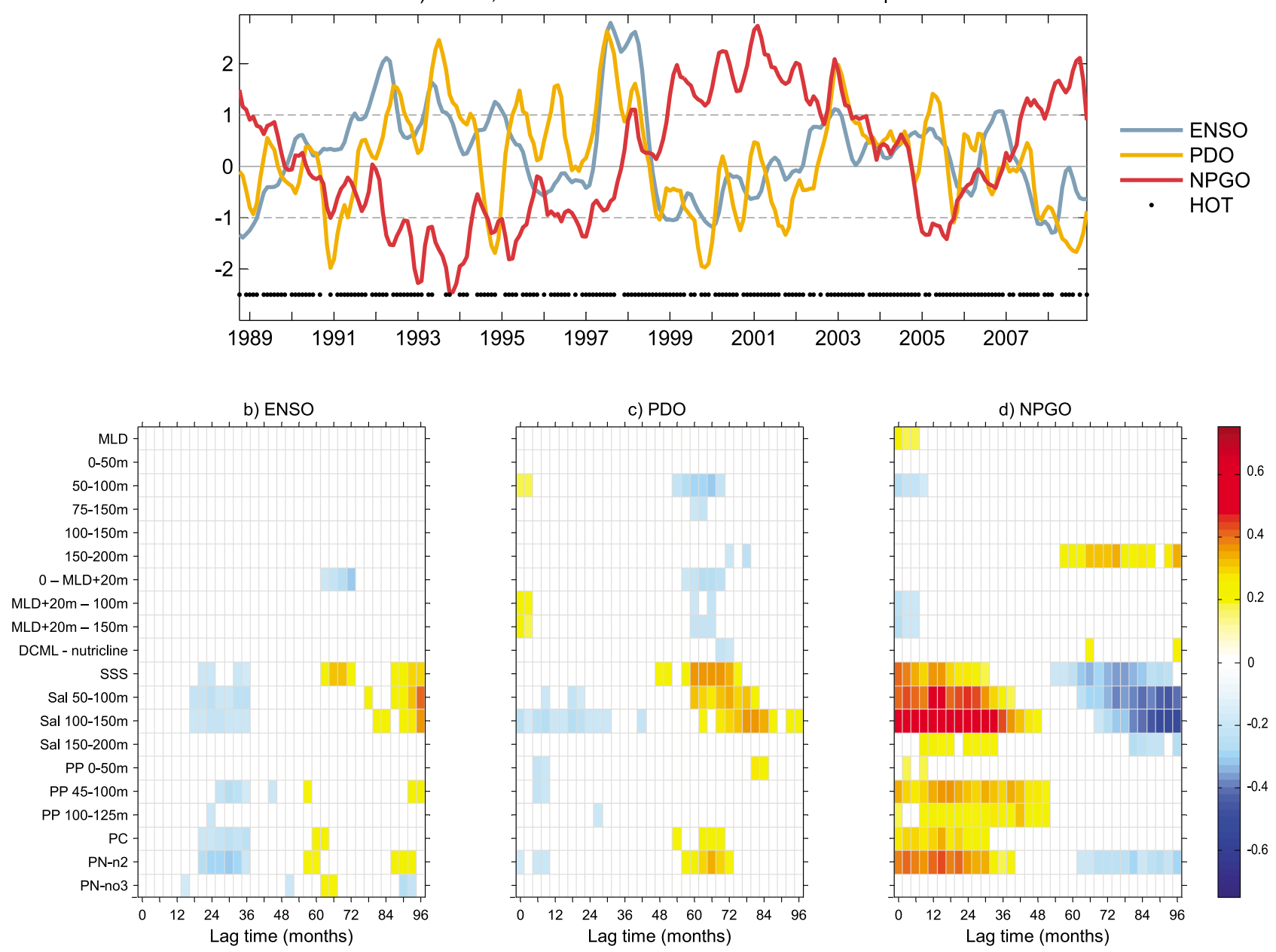

Figure 5. Comparison of basin-scale climate variability to HOT Station ALOHA. (a) The 3 month running means of the Multivariate ENSO Index (MEI, yellow), PDO Index (PDOI, blue), and NPGO index (red) over the HOT record. Black dots indicate months when HOT data were collected. Dotted lines delineate strongly positive and negative index values. Statistically significant $(p<0.01)$ linear correlations between the (b) MEI, (c) PDOI, and (d) NPGO indices and stratification and productivity time series at Station ALOHA. The color indicates the strength and sign of the correlation. The horizontal axis corresponds to monthly lags ranging from 0 to 96 months in increments of 3 months. The vertical axis corresponds to specific properties measured at Station ALOHA.

produce the linkage between the NPGO and productivity at ALOHA are not clearly understood, the observational data suggest that the role of stratification is not dominant.

\subsection{Why No Interannual Linkages to Stratification?}

[42] Why is there no clear long-term correlation between the observed stratification variability at Station ALOHA and concurrent productivity variability? Inputs of allochthonous nutrients are required for the maintenance of new production, yet the mechanisms that supply these nutrients to surface photosynthesizers in the subtropical North Pacific are still not well understood. Episodic variability in new production at ALOHA has previously been suggested to result from nutrient injections caused by meteorological upwelling events, eddies and planetary waves [Letelier et al., 2000; Sakamoto et al., 2004; Fong et al., 2008;
Mahaffey et al., 2008; Nicholson et al., 2008; Rii et al., 2008]. Consideration of this type of stochastic nutrient loading may be essential, since the continuous upward nutrient fluxes derived from observed and modeled openocean turbulent diffusivities have historically been considered insufficient to support observed rates of new production in the subtropical gyres [Lewis et al., 1986; Ledwell et al., 1993; McGillicuddy et al., 1998]. However, the regular, monthly HOT sampling program is not ideally suited for detecting episodic variability in stratification, nutrient fluxes and productivity [Karl et al., 2003]. Higher-frequency observation programs using moored sensors have been implemented at the HALE ALOHA site, but these have not been long enough to support robust interannual and decadal assessments. 
a) $\operatorname{MLD}(m)$

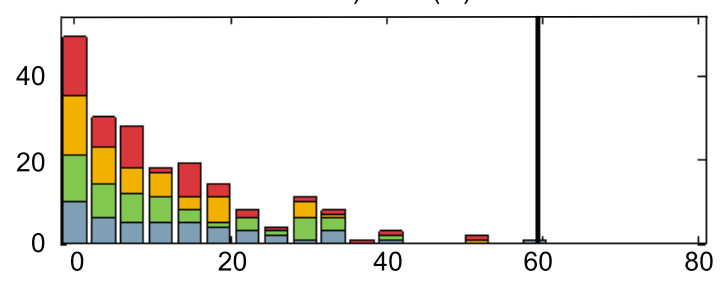

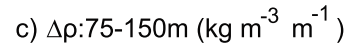

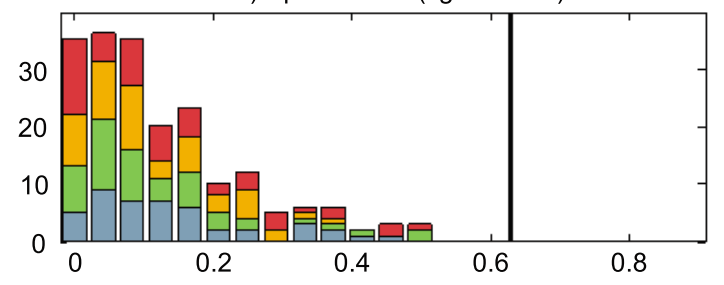

e) PP @ 75m $\left(\mathrm{mg} \mathrm{C} \mathrm{m}^{-3}\right)$

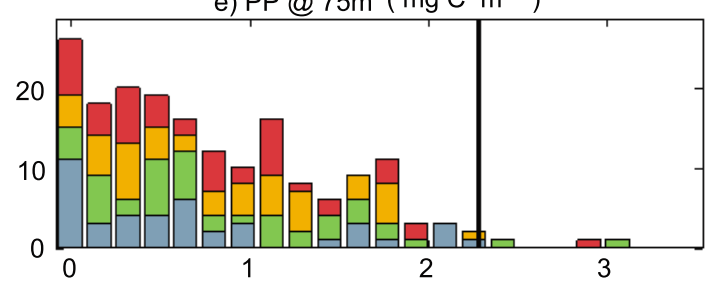

g) N2-supported PN flux $\left(\mathrm{mg} \mathrm{m}^{-3}\right.$ day $\left.^{-1}\right)$

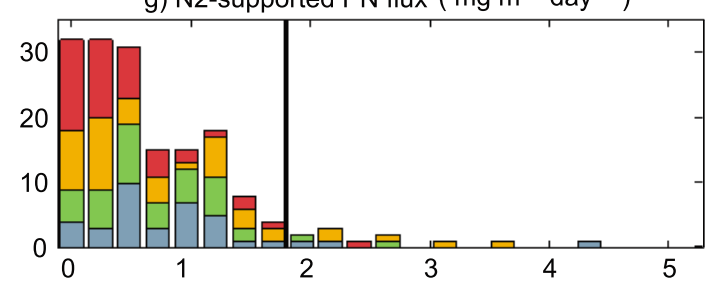

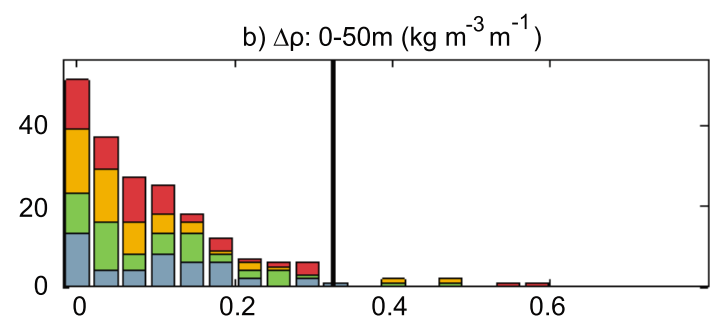

d) PP @ $25 \mathrm{~m}\left(\mathrm{mg} \mathrm{C} \mathrm{m}^{-3}\right)$

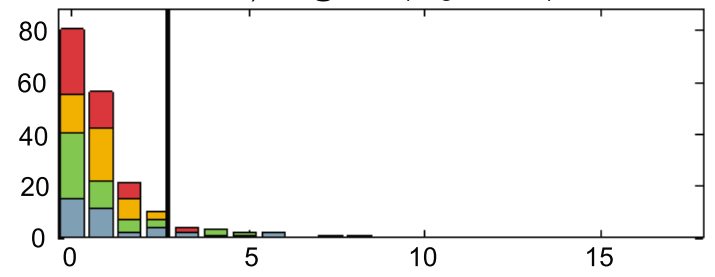

f) PP @ 100m $\left(\mathrm{mg} \mathrm{C} \mathrm{m}^{-3}\right)$

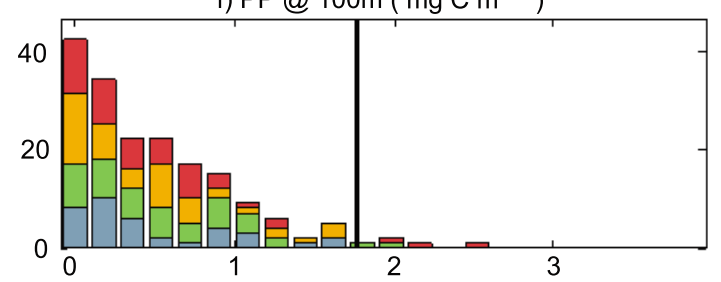

h) NO3-supported PN flux ( $\mathrm{mg} \mathrm{m}^{-3}$ day ${ }^{-1}$ )

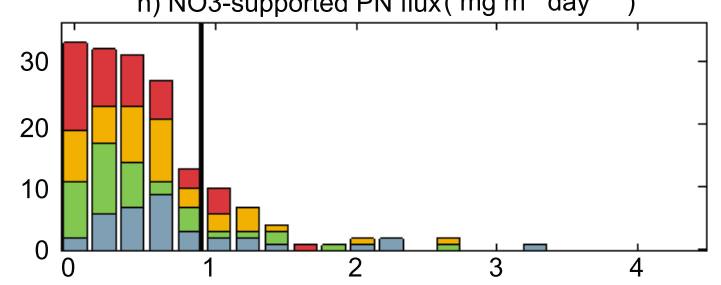

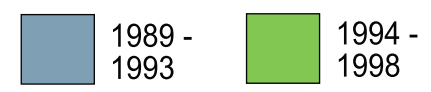

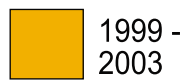

2004 -

2008

Figure 6. A stacked histogram of anomalies in stratification and productivity from 1988 to 2008 at Station ALOHA. The $x$ axis shows the absolute magnitude of anomalies of each property (calculated by subtracting the long-term monthly mean) as well as the magnitude of the seasonal range (indicated by a solid black line). Colors are used to separate the anomalies within each bin into distinct 5 year periods (pentads) within the HOT record: 1989-1993 (blue), 1994-1998 (green), 1999-2003 (yellow), and 2004-2008 (red). (a) Mixed layer depth; (b) upper layer stratification, assessed as $\rho_{50}-\rho_{0}$; (c) lower layer stratification, assessed as $\rho_{150}-\rho_{75}$; primary productivity rates measured in the (d) upper $(25 \mathrm{~m})$, (e) middle $(75 \mathrm{~m})$, and (f) lower $(100 \mathrm{~m})$ euphotic zone; and the (g) $\mathrm{N}_{2^{-}}$and (h) $\mathrm{NO}_{3}$-supported fractions of the particulate nitrogen flux, measured at $150 \mathrm{~m}$ are shown.

[43] The observational record at Station ALOHA does offer another potential explanation for the lack of a correlative relationship between productivity and stratification over interannual time scales. Figure 6 presents a comparison of the magnitudes of seasonal and interannual variability in stratification and productivity measured throughout the euphotic zone at this location. For each property, the histogram shows that the majority of monthly anomalies observed over the past two decades are smaller in magnitude than the average seasonal range (indicated by a solid line).
The strength of the seasonal signal relative to interannual variability could potentially explain the correlations (or lack thereof) between stratification and productivity on seasonal and interannual time scales. In the upper euphotic zone, for example, while summertime stratification increases are apparently are great enough to significantly decrease nutrient supply, enhance nitrogen fixation and produce summer blooms [White et al., 2007; Dore et al., 2008], stratification variations on interannual time scales may not be great enough to alter nutrient supply to a comparable degree. 
Dividing the data set by time into pentads (indicated by different colors in Figure 6) does not reveal a clear temporal bias in the magnitude of the anomalies, including before and after the aforementioned 1998 ENSO/PDO transition. Similarly, no temporal bias is observed when the data are divided by season (not shown). It appears that forcing from stratification changes at this location has consistently not been strong enough over the observational record to produce a consistent or coherent productivity response.

\section{Conclusions}

[44] Over the time span of the HOT data set (1988-2008) we conclude that there has been no consistent correlation between interannual variability in productivity and stratification at any depths within the euphotic zone. Indeed, the general biological and physical coupling that is strongly evident at seasonal time scales appears to vanish over longer time scales. Additionally, there is no clear or consistent pattern of correlation between local stratification or productivity at Station ALOHA and ENSO or PDO variability. The absence of evidence for a linkage to these climate processes may reflect the lack of a strong or consistent expression of ENSO or PDO signals at this location. A comparison of local ecosystem variability with the NPGO, however, reveals an intriguing correlation that has distinct structure in depth space and in time. While local stratification variability at Station ALOHA is uncorrelated with the NPGO index, a similar pattern of correlation does emerge between the NPGO and both productivity and salinity in the middle euphotic zone at this location. While the salinity correlation can be interpreted as evidence of a direct NPGO control on local hydrography, probably via NPTW variability, the question of how exactly NPGO variability could impact productivity and, specifically, nitrogen fixation at ALOHA remains unanswered.

[45] Whatever the mechanisms are that create the observed linkages between local productivity and basinwide climate variability, the observational evidence shows that local stratification does not play a primary role. Stratification variability is not correlated with climate forcing and has simply not engendered a strong or consistent productivity response at this location over the last 2 decades. This result must be considered in the context of the complexity and nonlinearity of the biological systems being observed, as well as the limitations of a regular, monthly observation program in a setting of potentially significant stochastic processes. However, another explanation for the general absence of strong correlative relationships on interannual time scales, is that the observations at ALOHA simply document a very strongly seasonally forced ecosystem.

[46] The HOT and BATS records both provide evidence of a nonconsistent response of subtropical productivity to forcing from interannual stratification variability, but apparently for different reasons. Primary productivity at BATS, which is driven by seasonal destratification, seems primed to respond negatively to future increases in upper ocean stability. The absence of correlation here reflects the complicating influence of other dynamics that affect vertical mixing and nutrient supply. The results at Station ALOHA, where seasonal destratification is not as strong or important, probably reflect instead the internal dynamics of a perma- nent two-layer ecosystem model in a setting of weak interannual physical forcing. The degree to which these differences indicate fundamental dissimilarities between the Atlantic and Pacific hinges on the extent to which the HOT and BATS records are representative of their respective basins. An important consideration, then, is the relative location of each time series station within its gyre. BATS is located in the northwestern portion of the North Atlantic Subtropical gyre, a region characterized by vigorous circulation and strong seasonal wind and buoyancy forcing. The HOT program samples the relatively quiescent environment of the southern and eastern recirculation zone of the North Pacific Subtropical gyre. It is interesting to consider whether observations at ALOHA might resemble more closely those at BATS, if Station ALOHA had been positioned farther enough to the north and west. In this respect it may be that, collectively, the HOT and BATS data sets might contribute to a single, comprehensive view of a generalized subtropical gyre.

[47] Acknowledgments. This work was supported by funding from the National Science Foundation and the North Carolina Space Grant Graduate Student Fellowship Program. We gratefully acknowledge the valuable and ongoing work of the Hawaiian Ocean Time series program. We would especially like to acknowledge the advice and feedback offered by N. Cassar during the course of this study.

\section{References}

Ayers, J. M., and M. S. Lozier (2010), Physical controls on the seasonal migration of the North Pacific transition zone chlorophyll front, J. Geophys. Res., 115, C05001, doi:10.1029/2009JC005596.

Behrenfeld, M. J. (2010), Abandoning Sverdrup's critical depth hypothesis on phytoplankton blooms, Ecology, 91(4), 977-989, doi:10.1890/091207.1.

Behrenfeld, M. J., R. T. O’Malley, D. A. Siegel, C. R. McClain, J. L. Sarmiento, G. C. Feldman, A. J. Milligan, P. G. Falkowski, R. M. Letelier, and E. S. Boss (2006), Climate-driven trends in contemporary ocean productivity, Nature, 444(7120), 752-755, doi:10.1038/nature05317.

Bidigare, R. R., F. Chai, M. R. Landry, R. Lukas, C. C. S. Hannides, S. J. Christensen, D. M. Karl, L. Shi, and Y. Chao (2009), Subtropical ocean ecosystem structure changes forced by North Pacific climate variations, J. Plankton Res., 31(10), 1131-1139, doi:10.1093/plankt/fbp064.

Bopp, L., P. Monfray, O. Aumont, J. L. Dufresne, H. Le Treut, G. Madec, L. Terray, and J. C. Orr (2001), Potential impact of climate change on marine export production, Global Biogeochem. Cycles, 15(1), 81-99, doi:10.1029/1999GB001256.

Boyd, P. W., and S. C. Doney (2002), Modelling regional responses by marine pelagic ecosystems to global climate change, Geophys. Res. Lett., 29(16), 1806, doi:10.1029/2001GL014130.

Brix, H., N. Gruber, D. M. Karl, and N. R. Bates (2006), On the relationships between primary, net community, and export production in subtropical gyres, Deep Sea Res. Part II, 53(5-7), 698-717, doi:10.1016/j. dsr2.2006.01.024.

Cermeno, P., S. Dutkiewicz, R. P. Harris, M. Follows, O. Schofield, and P. G. Falkowski (2008), The role of nutricline depth in regulating the ocean carbon cycle, Proc. Natl. Acad. Sci. U. S. A., 105(51), 20,344-20,349, doi:10.1073/pnas.0811302106.

Chelton, D. B., M. G. Schlax, M. H. Freilich, and R. F. Milliff (2004), Satellite measurements reveal persistent small-scale features in ocean winds, Science, 303(5660), 978-983, doi:10.1126/science.1091901.

Church, M. J., C. Mahaffey, R. M. Letelier, R. Lukas, J. P. Zehr, and D. M. Karl (2009), Physical forcing of nitrogen fixation and diazotroph community structure in the North Pacific subtropical gyre, Global Biogeochem. Cycles, 23, GB2020, doi:10.1029/2008GB003418.

Corno, G., D. M. Karl, M. J. Church, R. M. Letelier, R. Lukas, R. R. Bidigare, and M. R. Abbott (2007), Impact of climate forcing on ecosystem processes in the North Pacific Subtropical Gyre, J. Geophys. Res., 112, C04021, doi:10.1029/2006JC003730.

Corno, G., R. M. Letelier, M. R. Abbott, and D. M. Karl (2008), Temporal and vertical variability in photosynthesis in the North Pacific Subtropical Gyre, Limnol. Oceanogr., 53(4), 1252-1265. 
Di Lorenzo, E., et al. (2008), North Pacific Gyre Oscillation links ocean climate and ecosystem change, Geophys. Res. Lett., 35, L08607, doi:10.1029/2007GL032838.

Doney, S. C. (2006), Oceanography: Plankton in a warmer world, Nature, 444(7120), 695-696, doi:10.1038/444695a

Dore, J. E., J. R. Brum, L. M. Tupas, and D. M. Karl (2002), Seasonal and interannual variability in sources of nitrogen supporting export in the oligotrophic subtropical North Pacific Ocean, Limnol. Oceanogr., 47(6), 1595-1607, doi:10.4319/1o.2002.47.6.1595.

Dore, J. E., R. M. Letelier, M. J. Church, R. Lukas, and D. M. Karl (2008), Summer phytoplankton blooms in the oligotrophic North Pacific Subtropical Gyre: Historical perspective and recent observations, Prog. Oceanogr., 76(1), 2-38, doi:10.1016/j.pocean.2007.10.002.

Dugdale, R. C. (1967), Nutrient limitation in sea: Dynamics identification and significance, Limnol. Oceanogr., 12(4), 685-695, doi:10.4319/ lo.1967.12.4.0685

Emery, W. J., and J. S. Dewar (1982), Mean temperature-salinity, salinitydepth and temperature-depth curves for the North Atlantic and the North Pacific, Prog. Oceanogr., 11(3), 219-256, doi:10.1016/0079-6611(82) 90015-5.

Eppley, R. W., E. H. Renger, E. L. Venrick, and M. M. Mullin (1973), Study of plankton dynamics and nutrient cycling in central gyre of North Pacific Ocean, Limnol. Oceanogr., 18(4), 534-551, doi:10.4319/ lo.1973.18.4.0534.

Falkowski, P. G., and M. J. Oliver (2007), Mix and match: How climate selects phytoplankton, Nat. Rev. Microbiol., 5(10), 813-819, doi:10.1038/ nrmicro1751.

Fennel, K., and E. Boss (2003), Subsurface maxima of phytoplankton and chlorophyll: Steady-state solutions from a simple model, Limnol. Oceanogr., 48(4), 1521-1534, doi:10.4319/lo.2003.48.4.1521.

Follows, M., and S. Dutkiewicz (2002), Meteorological modulation of the North Atlantic spring bloom, Deep Sea Res. Part II, 49(1-3), 321-344.

Fong, A. A., D. M. Karl, R. Lukas, R. M. Letelier, J. P. Zehr, and M. J. Church (2008), Nitrogen fixation in an anticyclonic eddy in the oligotrophic North Pacific Ocean, ISME J., 2(6), 663-676, doi:10.1038/ismej. 2008.22

Grabowski, M. N. W., M. J. Church, and D. M. Karl (2008), Nitrogen fixation rates and controls at Stn ALOHA, Aquat. Microb. Ecol., 52(2), 175-183, doi:10.3354/ame01209.

Gregg, W. W., N. W. Casey, and C. R. McClain (2005), Recent trends in global ocean chlorophyll, Geophys. Res. Lett., 32, L03606, doi:10.1029/ 2004GL021808.

Gruber, N., C. D. Keeling, and N. R. Bates (2002), Interannual variability in the North Atlantic Ocean carbon sink, Science, 298(5602), 2374-2378, doi:10.1126/science.1077077.

Huisman, J., N. N. P. Thi, D. M. Karl, and B. Sommeijer (2006), Reduced mixing generates oscillations and chaos in the oceanic deep chlorophyll maximum, Nature, 439(7074), 322-325, doi:10.1038/nature04245.

Irwin, A. J., and M. J. Oliver (2009), Are ocean deserts getting larger?, Geophys. Res. Lett., 36, L18609, doi:10.1029/2009GL039883.

Karl, D. M. (1999), A sea of change: Biogeochemical variability in the North Pacific Subtropical Gyre, Ecosystems, 2(3), 181-214, doi:10.1007/s100219900068.

Karl, D. M., and R. Lukas (1996), The Hawaii Ocean Time-series (HOT) program: Background, rationale and field implementation, Deep Sea Res. Part II, 43(2-3), 129-156, doi:10.1016/0967-0645(96)00005-7.

Karl, D. M., R. Letelier, D. Hebel, L. Tupas, J. Dore, J. Christian, and C. Winn (1995), Ecosystem changes in the North Pacific Subtropical Gyre attributed to the 1991-92 El-Nino, Nature, 373(6511), 230-234, doi:10.1038/373230a0

Karl, D. M., J. R. Christian, J. E. Dore, D. V. Hebel, R. M. Letelier, L. M Tupas, and C. D. Winn (1996), Seasonal and interannual variability in primary production and particle flux at Station ALOHA, Deep Sea Res. Part II, 43(2-3), 539-568, doi:10.1016/0967-0645(96)00002-1.

Karl, D., R. Letelier, L. Tupas, J. Dore, J. Christian, and D. Hebel (1997), The role of nitrogen fixation in biogeochemical cycling in the subtropical North Pacific Ocean, Nature, 388(6642), 533-538, doi:10.1038/41474.

Karl, D. M., R. R. Bidigare, and R. M. Letelier (2001), Long-term changes in plankton community structure and productivity in the North Pacific Subtropical Gyre: The domain shift hypothesis, Deep Sea Res. Part II, 48(8-9), 1449-1470, doi:10.1016/S0967-0645(00)00149-1.

Karl, D. M., E. A. Laws, P. Morris, P. J. L. Williams, and S. Emerson (2003), Global carbon cycle: Metabolic balance of the open sea, Nature, 426(6962), 32, doi:10.1038/426032a.

Ledwell, J. R., A. J. Watson, and C. S. Law (1993), Evidence for slow mixing across the pycnocline from an open-ocean tracer-release experiment Nature, 364(6439), 701-703, doi:10.1038/364701a0.

Letelier, R. M., R. R. Bidigare, D. V. Hebel, M. Ondrusek, C. D. Winn, and D. M. Karl (1993), Temporal variability of phytoplankton community structure-based on pigment analysis, Limnol. Oceanogr., 38(7), 1420-1437, doi:10.4319/1o.1993.38.7.1420.

Letelier, R. M., D. M. Karl, M. R. Abbott, P. Flament, M. Freilich, R. Lukas, and T. Strub (2000), Role of late winter mesoscale events in the biogeochemical variability of the upper water column of the North Pacific Subtropical Gyre, J. Geophys. Res., 105(C12), 28,723-28,739, doi:10.1029/1999JC000306.

Letelier, R. M., D. M. Karl, M. R. Abbott, and R. R. Bidigare (2004), Light driven seasonal patterns of chlorophyll and nitrate in the lower euphotic zone of the North Pacific Subtropical Gyre, Limnol. Oceanogr., 49(2), 508-519, doi:10.4319/lo.2004.49.2.0508

Lewis, M. R., W. G. Harrison, N. S. Oakey, D. Hebert, and T. Platt (1986), Vertical nitrate fluxes in the oligotrophic ocean, Science, 234(4778), 870-873, doi:10.1126/science.234.4778.870.

Lozier, M. S., W. B. Owens, and R. G. Curry (1995), The climatology of the North Atlantic, Prog. Oceanogr., 36(1), 1-44, doi:10.1016/00796611(95)00013-5.

Lukas, R. (2001), Freshening of the upper thermocline in the North Pacific subtropical gyre associated with decadal changes of rainfall, Geophys. Res. Lett., 28(18), 3485-3488, doi:10.1029/2001GL013116.

Lukas, R., and F. Santiago-Mandujano (2008), Interannual to interdecadal salinity variations observed near Hawaii: Local and remote forcing by surface freshwater fluxes, Oceanography, 21(1), 46-55.

Macdonald, A. M., T. Suga, and R. G. Curry (2001), An isopycnally averaged North Pacific climatology, J. Atmos. Oceanic Technol., 18(3), 394-420, doi:10.1175/1520-0426(2001)018<0394:AIANPC $>2.0 . C O ; 2$.

Mahaffey, C., C. R. Benitez-Nelson, R. R. Bidigare, Y. Rii, and D. M. Karl (2008), Nitrogen dynamics within a wind-driven eddy, Deep Sea Res. Part II, 55(10-13), 1398-1411, doi:10.1016/j.dsr2.2008.02.004.

Mantua, N. J., S. R. Hare, Y. Zhang, J. M. Wallace, and R. C. Francis (1997), A Pacific interdecadal climate oscillation with impacts on salmon production, Bull. Am. Meteorol. Soc., 78(6), 1069-1079, doi:10.1175/ 1520-0477(1997)078<1069:APICOW>2.0.CO;2

McClain, C. R., S. R. Signorini, and J. R. Christian (2004), Subtropical gyre variability observed by ocean-color satellites, Deep Sea Res. Part II, 51(1-3), 281-301, doi:10.1016/j.dsr2.2003.08.002.

McGillicuddy, D. J., A. R. Robinson, D. A. Siegel, H. W. Jannasch, R. Johnson, T. Dickeys, J. McNeil, A. F. Michaels, and A. H. Knap (1998), Influence of mesoscale eddies on new production in the Sargasso Sea, Nature, 394(6690), 263-266, doi:10.1038/28367.

Menzel, D. W., and J. H. Ryther (1961), Annual variations in primary production of the Sargasso Sea off Bermuda, Deep Sea Res., 7(4), 282-288, doi:10.1016/0146-6313(61)90046-6.

Nicholson, D., S. Emerson, and C. C. Eriksen (2008), Net community production in the deep euphotic zone of the subtropical North Pacific gyre from glider surveys, Limnol. Oceanogr., 53(5), 2226-2236.

Palter, J. B., M. S. Lozier, and R. T. Barber (2005), The effect of advection on the nutrient reservoir in the North Atlantic Subtropical Gyre, Nature, 437(7059), 687-692, doi:10.1038/nature03969.

Polovina, J. J., E. A. Howell, and M. Abecassis (2008), Ocean's least productive waters are expanding, Geophys. Res. Lett., 35, L03618, doi:10.1029/2007GL031745.

Rii, Y. M., S. L. Brown, F. Nencioli, V. Kuwahara, T. Dickey, D. M. Karl, and R. R. Bidigare (2008), The transient oasis: Nutrient-phytoplankton dynamics and particle export in Hawaiian lee cyclones, Deep Sea Res. Part II, 55(10-13), 1275-1290, doi:10.1016/j.dsr2.2008.01.013.

Sakamoto, C. M., D. M. Karl, H. W. Jannasch, R. R. Bidigare, R. M. Letelier, P. M. Walz, J. P. Ryan, P. S. Polito, and K. S. Johnson (2004), Influence of Rossby waves on nutrient dynamics and the plankton community structure in the North Pacific Subtropical Gyre, J. Geophys. Res., 109, C05032, doi:10.1029/2003JC001976.

Sarmiento, J. L., et al. (2004), Response of ocean ecosystems to climate warming, Global Biogeochem. Cycles, 18, GB3003, doi:10.1029/ 2003 GB002134.

Schmittner, A. (2005), Decline of the marine ecosystem caused by a reduction in the Atlantic overturning circulation, Nature, 434(7033), 628-633, doi:10.1038/nature03476.

Smith, R. B., and V. Grubisic (1993), Aerial observations of Hawaii wake, J. Atmos. Sci., 50(22), 3728-3750, doi:10.1175/1520-0469(1993) $050<3728$ :AOOHW>2.0.CO;2.

Stammer, D., S. Park, A. Kohl, R. Lukas, and F. Santiago-Mandujano (2008), Causes for large-scale hydrographic changes at the Hawaii Ocean time series station, J. Phys. Oceanogr., 38(9), 1931-1948, doi:10.1175/ 2008JPO3751.1.

Suga, T., A. Kato, and K. Hanawa (2000), North Pacific Tropical Water: Its climatology and temporal changes associated with the climate regime shift in the 1970s, Prog. Oceanogr., 47(2-4), 223-256, doi:10.1016/ S0079-6611(00)00037-9. 
Suga, T., K. Motoki, Y. Aoki, and A. M. Macdonald (2004), The North Pacific climatology of winter mixed layer and mode waters, J. Phys. Oceanogr., 34(1), 3-22, doi:10.1175/1520-0485(2004)034<0003: TNPCOW $>2.0 . \mathrm{CO} ; 2$

Sverdrup, H. U. (1953), On conditions for the vernal blooming of phytoplankton, ICES J. Mar. Sci., 18(3), 287-295, doi:10.1093/icesjms/ 18.3.287.

Ueyama, R., and B. C. Monger (2005), Wind-induced modulation of seasonal phytoplankton blooms in the North Atlantic derived from satellite observations, Limnol. Oceanogr., 50(6), 1820-1829, doi:10.4319/ lo.2005.50.6.1820.

Venrick, E. L. (1982), Phytoplankton in an oligotrophic ocean: Observations and questions, Ecol. Monogr., 52(2), 129-154, doi:10.2307/ 1942608.

Venrick, E. L. (1993), Phytoplankton seasonality in the central North Pacific: The endless summer reconsidered, Limnol. Oceanogr., 38(6), 1135-1149, doi:10.4319/lo.1993.38.6.1135.
White, A. E., Y. H. Spitz, and R. M. Letelier (2007), What factors are driving summer phytoplankton blooms in the North Pacific Subtropical Gyre?, J. Geophys. Res., 112, C12006, doi:10.1029/2007JC004129.

Williams, R. G., and M. J. Follows (1998), The Ekman transfer of nutrients and maintenance of new production over the North Atlantic, Deep Sea Res. Part I, 45(2-3), 461-489, doi:10.1016/S0967-0637(97)00094-0.

Winn, C. D., L. Campbell, J. R. Christian, R. M. Letelier, D. V. Hebel, J. E. Dore, L. Fujieki, and D. M. Karl (1995), Seasonal Variability in the phytoplankton community of the North Pacific Subtropical Gyre, Global Biogeochem. Cycles, 9(4), 605-620, doi:10.1029/95GB02149.

Xie, S. P., W. T. Liu, Q. Y. Liu, and M. Nonaka (2001), Far-reaching effects of the Hawaiian islands on the Pacific ocean-atmosphere system, Science, 292(5524), 2057-2060, doi:10.1126/science.1059781.

A. C. Dave and M. S. Lozier, Division of Earth and Ocean Sciences, Nicholas School of the Environment, Duke University, Old Chemistry Building, Box 90227, Durham, NC 27708, USA. (apurva.dave@duke. edu; s.lozier@duke.edu) 